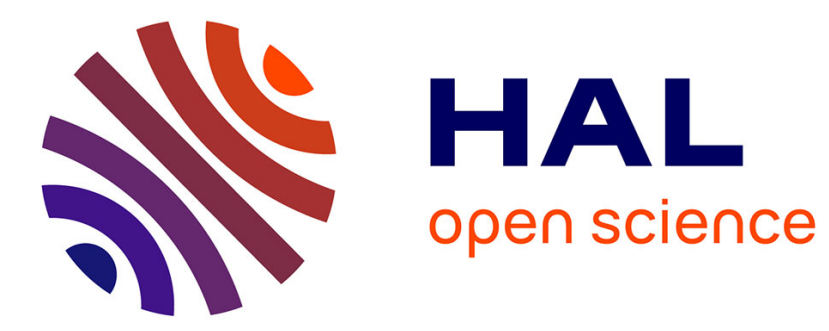

\title{
Economic costs of biological invasions in protected areas worldwide - where do we stand?
}

Desika Moodley, Elena Angulo, Ross Cuthbert, Brian Leung, Anna Turbelin, Ana Novoa, Melina Kourantidou, Gustavo Heringer, Phillip Haubrock, D

Renault, et al.

\section{To cite this version:}

Desika Moodley, Elena Angulo, Ross Cuthbert, Brian Leung, Anna Turbelin, et al.. Economic costs of biological invasions in protected areas worldwide - where do we stand?. 2021. hal-03427566

\section{HAL Id: hal-03427566 \\ https://hal.science/hal-03427566}

Preprint submitted on 18 Nov 2021

HAL is a multi-disciplinary open access archive for the deposit and dissemination of scientific research documents, whether they are published or not. The documents may come from teaching and research institutions in France or abroad, or from public or private research centers.
L'archive ouverte pluridisciplinaire HAL, est destinée au dépôt et à la diffusion de documents scientifiques de niveau recherche, publiés ou non, émanant des établissements d'enseignement et de recherche français ou étrangers, des laboratoires publics ou privés.

\section{(c)(1)}

Distributed under a Creative Commons Attribution| 4.0 International License 


\section{Z Research Square
They should not be considered conclusive, used to inform clinical practice,
or referenced by the media as validated information.}

\section{Economic costs of biological invasions in protected areas worldwide - where do we stand?}

Desika Moodley ( $\sim$ desikamoodley29@gmail.com )

Institute of Botany, The Czech Academy of Sciences https://orcid.org/0000-0002-0788-2136

\section{Elena Angulo}

Université Paris-Saclay: Universite Paris-Saclay

\section{Ross N. Cuthbert}

GEOMAR: Helmholtz-Zentrum fur Ozeanforschung Kiel

\section{Brian Leung}

McGill University

\section{Anna Turbelin}

Paris-South University: Universite Paris-Saclay

\section{Ana Novoa}

Institute of Botany Czech Academy of Sciences: Botanicky Ustav Akademie Ved Ceske Republiky

\section{Melina Kourantidou}

University of Southern Denmark: Syddansk Universitet

\section{Gustavo Heringer}

Universidade Federal de Lavras

\section{Phillip J. Haubrock}

Senckenberg Research Institutes and Natural History Museums: Senckenberg Gesellschaft fur Naturforschung

David Renault Universite de Rennes 1

\section{Marine Robuchon}

European Commission Joint Research Centre

\section{Jean Fantle-Lepczyk}

Auburn University

Franck Courchamp

Universite Paris-Saclay

\section{Christophe Diagne}

Universite Paris-Saclay

\section{Research Article}


Keywords: Invasive alien species, InvaCost, biodiversity conservation, monetary impacts, protected areas

Posted Date: March 24th, 2021

DOI: https://doi.org/10.21203/rs.3.rs-289130/v1

License: (c) (1) This work is licensed under a Creative Commons Attribution 4.0 International License. Read Full License 


\section{Abstract}

Biological invasions are one of the main threats to biodiversity within protected areas (PAs) worldwide. Meanwhile, the resilience of PAs along with their capacity to mitigate impacts from invasions remains largely unknown. Filling this knowledge gap is therefore critical for informing policy responses and optimally allocating resources invested in prevention and control strategies. Here we use the InvaCost database to address this gap from three perspectives: (i) characterizing the total cost of invasive alien species (IAS) in PAs; (ii) examining differences in mean observed costs of IAS between PAs and non-PAs; and (iii) evaluating factors affecting mean observed costs of IAS in PAs. Our results show that reported economic costs of IAS in PAs amounted to US\$22.13 billion between 1976 and 2020, of which US\$ 802.47 million were observed costs (incurred) and US\$21.18 billion were potential costs (expected). The highest observed total costs were reported for Africa and South America; mainly caused by mammals, plants and insects; and predominantly impacted the finances of government agencies. Most of the observed total costs were reported for management $(69 \%)$ versus damage $(27 \%)$, however, the vast majority of management costs were reported for post-invasion actions (US\$ 453 million; focused on control and eradication). PAs incurred on average higher costs than non-PAs, however, this was dependent on the environment and the continent. When analyzing costs of IAS within PAs, observed mean costs significantly differed with the environment (higher in terrestrial environments), continent (higher in Pacific islands), taxon (higher for vertebrates and invertebrates than in plants) and the human development index (developed countries incur higher costs). Managers of selected PAs surveyed acknowledged IAS as the most threatening factor, concurred on the necessity of reporting costs in PAs, and pointed to insufficient budget allocation for pre-invasion actions. Our findings highlight the need for a deeper understanding of the economic costs caused by invasions across PAs, direct driving factors and management challenges.

\section{Introduction}

Biological invasions represent a global environmental problem and present a management challenge for humanity (Pyšek et al. 2020; Ricciardi et al. 2021). The plethora of environmental impacts posed by invasive alien species (IAS) range from declines in biodiversity (Ellstrand and Schierenbeck 2000; Vilà et al. 2000; Hejda et al. 2009; Butchart et al. 2010) to disruption of ecological processes and affects the provisioning of ecosystem services (Vitousek 1990; Charles and Dukes 2008; Pejchar and Mooney 2009; Ehrenfeld 2010). IAS are also responsible for detrimental impacts on human health and well-being (Conn 2014; Hulme 2014; Mazza and Tricarico 2018; Schaffner et al. 2020), and cause losses to multiple sectors of the economy (Pimentel et al. 2005; Colautti et al. 2006; Martins et al. 2006; Xu et al. 2006; Kettunen et al. 2009; Engeman et al. 2010; Hoffmann and Broadhurst 2016; Pratt et al. 2017; Diagne et al. in press-a). Alarmingly, with no signs of abatement in the numbers of established alien species in recent decades, their associated environmental, social and economic impacts will likely continue to dramatically increase in the foreseeable future (Seebens et al. 2017, 2020; Bailey et al. 2020). As a result, there is an urgent need for establishing effective management responses. One way of achieving this is by effectively 
managing IAS in areas that protect a broad range of species and habitats, such as protected areas (PAs) - a pillar for global biodiversity conservation efforts.

Although PAs are the primary defence against biodiversity loss, one-third of the global protected land is under intense human pressure (Jones et al. 2018). Moreover, PAs tend to be more vulnerable and challenged by IAS, compared to other unprotected landscapes, since they often host a larger proportion of native, endemic and threatened species which are less adapted to anthropogenic disturbances (Foxcroft et al. 2013; Heringer et al. 2020). With 15\% of the global land surface and $\sim 7.6 \%$ of the ocean (www.protectedplanet.net/) currently covered in the network of PAs, the designation of PAs has been a critical means of mitigating biodiversity threats worldwide. PAs comprise a large range of designations with different management regimes, ranging from highly to minimally protected sites. In addition, the European Union plans to protect $30 \%$ of its land and sea territory by 2030 (https://eur-lex.europa.eu/legalcontent/EN/TXT/?uri=CELEX:52020DC0380). When appropriately designed and successfully managed, PAs can be effective in conserving native biodiversity (including species of conservation concern), maintaining ecosystem function and keeping ecosystem services intact (Chape et al. 2005; Foxcroft et al. 2011; Geldmann et al. 2013; Daněk et al. 2017; Ziller et al. 2020). Effectiveness of PAs for biodiversity conservation can be measured in many different ways, depending on the conservation goals in place. For example, the PA network design can be assessed to determine diversity of species and habitats, and/or inclusion of highest priority conservation areas to meet global biodiversity conservation goals (Rodrigues and Gaston 2001; Rodrigues et al. 2004; Le Saout et al. 2013; Heringer et al. 2020). In addition, one can evaluate management efficacy in terms of staff, equipment, budget and other resourcing necessities (Leverington et al. 2010).

Recent efforts have been made to improve analyses of invasion costs for specific taxonomic groups (Haubrock et al. in this issue; Bradshaw et al. 2016) or across various regions (Scalera 2010; Hoffmann and Broadhurst 2016; Kourantidou et al. in press; Crystal-Ornelas et al. in press; Diagne et al. in press-b; Haubrock et al. in press; Heringer et al. in press; Liu et al. 2021) and habitats (Lopez-Vaamonde et al. 2010; Paini et al. 2016; Cuthbert et al. in press; Renault et al. in this issue). However, a detailed understanding of the costs incurred by IAS is still lacking for PAs. This is despite the fact that understanding costs of IAS is critical to ensure adequate funding for conservation efforts and to design appropriate management actions that will help mitigate impacts and safeguard biodiversity (Dana et al. 2014; Diagne et al. 2020a). A preliminary analysis of the number of post-1970 English-language publications available in the Web of Science on costs of biological invasions (Supplementary Material 1), showed that despite the numerous IAS publications $(n=58,729)$, studies concerning PAs have received relatively little attention (12.6\%), and studies evaluating the economic costs in PAs are substantially lower (1.6\%). Overall, although skewed, IAS studies covering all three topics are steadily increasing through time.

Many of those studies have attempted to decipher the drivers of invasions in PAs (Gaertner et al. 2014; Gantchoff et al. 2018; lacarella et al. 2020; Liu et al. 2020; Moodley et al. 2020), thereby improving our understanding of the role of the designation type (i.e. nationally designated PAs, such as national parks, 
have fewer IAS), designation year (i.e. younger PAs have more IAS), PA size (i.e. larger PAs have more IAS) and/or human activities (e.g. IAS increase with accessibility and higher human footprint index) in driving the success and impacts of IAS in PAs (Gallardo et al. 2017; Liu et al. 2020). Yet, despite progress in our knowledge of these ecological and environmental drivers of invasions in PAs, their use as potential predictors of IAS economic costs remains unexplored. Moreover, while there is evidence that geographic bias (towards North America and the Pacific islands) and taxonomic bias (towards plants and insects) largely drive our understanding of IAS success and impact (Pysek et al. 2008; Hulme et al. 2014), thus far, there has been little effort made on exploring these pattern globally for IAS in PAs.

To fill the knowledge gap on the cost of biological invasions in PAs worldwide, we structured our study around four broad aims. Specifically, we sought to: 1) characterize the overall costs of IAS within PAs, based on temporal, spatial and taxonomic descriptors, as well as descriptors for the type of costs and sectors impacted; 2) compare costs of IAS between protected and non-protected areas by examining factors affecting differences in economic costs; 3 ) describe which cost and PA characteristics drive differences in IAS related expenditures across PAs registered in the World Database on Protected Areas; and 4) obtain insights and perspectives from PA managers regarding these costs and the various challenges they face.

\section{Materials And Methods}

\section{Original data}

We used information from the InvaCost database, the most recent, comprehensive database on globally reported economic costs of IAS in English and ten other languages (Angulo et al. in press; Diagne et al. 2020b). The database was built using standardized searches from different sources: ISI Web of Science platform (https://webofknowledge.com/), Google Scholar (https://scholar.google.com/), the Google search engine (https://www.google.com/) and targeted searches (i.e. via web page searches and experts/stakeholders consultations for documents or files containing cost information). Each database entry contains a cost value associated to a unique combination of cost descriptors, including: (i) the bibliographic information of the documents reporting the costs; (ii) the information on the impacted area (e.g. location, spatial scale, environment, and whether the location corresponded to a protected area); (iii) the taxonomy of the IAS causing the cost, (iv) the temporal extent over which the cost occurred, or was predicted to occur; and ( $v$ ) the typology of each reported cost (e.g. type of cost - management actions or economic damages; impacted sector - which activity, market or societal sector was related to the cost; and the reliability of the source document provided the cost estimate). To allow for comparable cost values, all cost estimates were standardized and converted to 2017 US\$ (Diagne et al. 2020b). For this study, we used the most up-to-date version of the InvaCost database (version 3.0 containing 9,823 entries; openly available at https://doi.org/10.6084/m9.figshare.12668570). We first re-classified some of the original columns of the database to ensure that our study is comparable with other PA studies (Table 1) and then filtered and extracted the data in different subsets as described below (all subsets are available in Supplementary Material 2). 


\section{Data processing}

\section{Subset preparation: the robust and expanded subsets}

To obtain a robust subset from the original database, we first excluded cost entries that were deemed less reliable (Fig. 1). Specifically, we filtered the Reliability cost descriptor column of our database to only select those costs characterised as having "high" reliability. This distinction of the cost entries into having "high" or "low" reliability, indicates if the approach used for cost estimation in the original source is reported, reproducible and traceable (see Diagne et al. 2020b for details on criteria used). Subsequently, we used the information provided in the Protected Area column to identify the status of land protection for each cost entry: "yes", only pertaining to protected areas; "no", only pertaining to non-protected areas; or "NA", when there was no information about the status or when costs were attached to both protected and non-protected areas. We excluded entries that were identified as "NA".

We further refined the resulting dataset to specifically address the aims of this study. Thus, we applied consecutive filtering procedures which resulted in the creation of four subsets (Fig. 1): (i) PA cost entries only (hereafter referred to as the Protected Area Robust Subset, see subset details below); (ii) costs for protected and unprotected areas together, which were then matched pairwise based on five cost descriptors (hereafter referred to as the Paired Subset, see subset details below); (iii) costs for PAs listed in the World Database on Protected Areas (WDPA; UNEP-WCMC and IUCN 2019), which allowed the addition of WDPA descriptor variables (hereafter referred to as the WPDA Subset, see subset details below); and from these (iv) selected national parks and reserves for the purposes of a pilot survey of PA managers' perceptions of costs related to IAS (hereafter referred to as the Survey Subset).

For homogenization purposes, all cost estimates were annualized in the original database (see 'Cost estimate per year' columns; Diagne et al. 2020b). Here, we expanded the Protected Area Subset, the Paired Subset and the WPDA Subset(Subsets i-iii in Fig. 1) to take into account the duration time (in years) of each cost estimate with the expandYearlyCosts function of the 'invacost' package version 0.3-4 (Leroy et al. 2020). This function relies on information contained in the Probable_starting_year_adjusted and Probable_ending_year_adjusted columns to repeat each annualized cost as many times as years of cost occurrence between 1976 and 2020. This resulted in comparable annual costs for all cost entries (i.e. expanded format) which are unbiased with respect to time.

\section{Averaging annualized costs estimates}

For the Paired Subset and the WDPA Subset(Subsets ii and iii in Fig. 1), we averaged the annual cost values across descriptors so that individual entries associated with a single species from the same location and environment, which incur the same type of costs and affect the same activity sectors, were automatically averaged into one single cost entry. To do this, we used the tapply function in base R on the following cost predictors: species, location, environment, continent, type of costs and activity sector (Fig. 1, Table 1, Supplementary Material 2 for the interpretation of these descriptive fields and the subsets). All the analyses presented in the main text were carried out with these expanded and averaged subsets. 


\section{The Protected Area Robust Subset}

Filtering entries classified as protected, resulted in the Protected Area Robust Subset with a total of 1,131 cost entries (9\% of InvaCost v3.0). This subset was then expanded (as explained above) to produce the Protected Area Subset with 3,687 entries which was used to qualitatively describe trends of economic costs associated with PAs (Subset $i$ in Fig. 1). Regarding the temporal variation of the costs of invasive species in PAs, we used the summarizeCosts function of the 'invacost' R package to quantify annual average costs at five-year intervals. We considered both the magnitude of costs (in US\$) as well as the number of cost entries (expanded) over time. Moreover, we examined costs over time separately for observed costs (i.e. if the cost was actually incurred) and for potential costs (i.e. if the cost was expected or predicted to occur) using the Implementation column. We also investigated the spatial distribution of PA associated costs by continents (classified according to Brummitt 2001), explored the taxonomic groups responsible for costs in PAs, and categorised the type of costs and the economic sectors impacted by the cost (details on these descriptors are available at https://doi.org/10.6084/m9.figshare.12668570).

\section{The Paired Subset}

A total of 2,542 cost entries were identified as occurring in non-PA areas (i.e. "no" in the protectedArea column) and constituted the Non-protected Area Robust Subset(Fig. 1). Both the Non-protected and the Protected Area Robust Subsets were filtered to only consider costs estimated at the unit or site spatial scales (i.e. excluding those estimated at country and regional scales), since this is comparable to the spatial scale in which PA costs occur. We also filtered cost entries by the Implementation column, retaining only "observed" costs (i.e. when the cost was actually incurred) and removing "potential" costs (i.e. when the cost was predicted and/or expected to occur over time within or beyond its actual distribution area). The resulting entries of the Protected Area Robust Subset and the Non-Protected Area Robust Subset were then paired using matching rows relating to their combined environment, taxonomic group, continent, type of cost, and impacted sector (See Table 1; Supplementary Material 2). Thus, we only retained cost entries containing the specified combination of these five descriptors in both the Protected Area Robust Subset and in the Non-protected Area Robust Subset, the entries with combinations that had no correspondence in one of the two subsets were excluded from the analysis. This resulted in a total of 1014 expanded and averaged paired entries (464 PA vs 550 non-PA entries), which constitutes the Paired Subset(Subset ii in Fig. 1) and was used to identify descriptors driving differences in costs between protected and unprotected areas.

\section{The Protected Area WDPA Subset}

Entries from the Protected Area Robust Subset that were also identified in the WDPA (UNEP-WCMC and IUCN 2019) were considered as the Protected Area WDPA Subset. This resulted in 505 expanded and averaged entries, and this subset was used to understand which descriptors drive the costs caused by IAS in PAs (Subset iii in Fig. 1). Here, we used eight descriptors; four were related to the characteristics of the PA and were obtained by searching the WDPA for: PA designation, PA designation year, PA surface area 
$\left(\mathrm{km}^{2}\right)$, and human development index; and four were related to the characteristics of the cost: continent, environment, taxonomic group of the IAS, and type of cost (Table 1; Supplementary Material 2).

\section{The Protected Area Survey Subset}

From the WDPA Subset, we only selected national parks or reserves to form part of the Protected Area Survey Subset(Subset iv in Fig. 1). This last subset was intended as a pilot case study to compare data from selected cases in InvaCost with data obtained directly from PA managers along with their perspectives to better understand the challenges they face in striving for effective management of IAS.

Table 1. Descriptors used to characterise the costs of invasive alien species: (a) descriptors of the costs and (b) descriptors of protected areas (see Supplementary Material 2 for the interpretation of these descriptive fields). Categories are added for each descriptor and a description or the range of continuous variables are given in parenthesis. Descriptors used in the analyses of protected and non-protected areas (i.e. Paired subset) and across protected areas (i.e. WDPA subset) are marked with crosses. Note that one category could not be paired in the PA subset (e.g. Antarctica), while the "economic sector" was not used in the WDPA subset due to the unbalanced sample size among categories. Sample size was 1,014 for the Paired subset and 505 for the WDPAsubset. For designation year and reported area, mean year was used for multiple entries. 


\begin{tabular}{|c|c|c|}
\hline Categories & $\begin{array}{l}\text { Paired } \\
\text { subset }\end{array}$ & $\begin{array}{l}\text { WPDA } \\
\text { subset }\end{array}$ \\
\hline \multicolumn{3}{|l|}{ (a) Cost descriptors } \\
\hline Continent & Africa & $x$ \\
\hline Antarctica & $x$ & \\
\hline Asia-Temperate & $x$ & $x$ \\
\hline Australasia & $x$ & $x$ \\
\hline Europe & $x$ & $x$ \\
\hline Northern America & $x$ & $x$ \\
\hline Southern America & $x$ & $x$ \\
\hline Pacific & $x$ & $x$ \\
\hline Taxonomic group & Invertebrate & $x$ \\
\hline Vertebrate & $x$ & $x$ \\
\hline Plant & $x$ & $x$ \\
\hline Other & $x$ & $x$ \\
\hline Environment & Aquatic & $x$ \\
\hline Semi-aquatic & $x$ & $x$ \\
\hline Terrestrial & $x$ & $x$ \\
\hline Diverse/unspecified & $x$ & $x$ \\
\hline Impacted sector & Agriculture & $x$ \\
\hline Authorities-Stakeholders & $x$ & \\
\hline Environment & $x$ & \\
\hline Health & $x$ & \\
\hline Mixed/Unspecified & $x$ & \\
\hline Type of cost & Pre-invasion management & $x$ \\
\hline Post-invasion management & $x$ & $x$ \\
\hline Knowledge \& Funding & $x$ & $x$ \\
\hline Mixed management & $x$ & $x$ \\
\hline $\begin{array}{l}\text { Mixed management \& } \\
\text { damage }\end{array}$ & $x$ & $x$ \\
\hline
\end{tabular}




\section{Damage \\ (b) Protected area descriptors}

$x$

$\times$

\begin{tabular}{llll} 
Designation & National Park & $\times$ \\
\hline Park & $\times$ & $\times$ & \\
\hline Terrestrial Reserve & $\times$ & \\
$\begin{array}{l}\text { Marine Protected } \\
\text { Area/Wetland }\end{array}$ & $\times$ & \\
$\begin{array}{l}\text { Areas of Special } \\
\text { Conservation }\end{array}$ & $\times$ & \\
$\begin{array}{l}\text { Other Terrestrial Protected } \\
\text { Areas }\end{array}$ & $\times$ & $\times$ \\
\hline Multiple & Year reported in WDPA (1889-2019) & $\times$ \\
\hline Designation year & Area reported in WDPA (0.05-25,468) & \\
\hline Reported area (Sq. km) & HDI Data 1990-2019 (0.528-0.957) & \\
\hline $\begin{array}{l}\text { Human Development Index } \\
\text { (HDI) }\end{array}$ & $\begin{array}{l}\text { (http://www.hdr.undp.org/en/data, accessed } \\
\end{array}$ & \\
\hline
\end{tabular}

\section{Online survey}

We used the Survey Monkey platform to develop a short survey (12 questions taking approximately 20 minutes) with the aim of collecting information on management costs of IAS in PAs, gaining insights from local managers on their perceptions and the challenges they face in IAS management (See Supplementary Material $\mathbf{3}$ for the full survey). Each survey was personalized in the title according to the name of the PA, as well as in the question relating to each PA's reported management costs (Question 12). The survey was sent via email and in English, however, the email text was translated to the native language of the country in which the PA was located. This resulted in surveys sent to PA managers of 16 national parks and 28 reserves spanning 15 countries. The timeline for survey completion was one month (8 October - 8 November 2020) with reminders sent biweekly in cases of no response. Given the few responses to the survey, we used the insights shared from managers, in a qualitative manner, to inform our findings.

\section{Statistical analyses}

Differences in economic costs inside and outside protected areas 
In order to identify differences in the economic costs of IAS between PAs and non-PAs, and to understand which descriptors could affect these differences, we performed a multiple linear regression using the data of the Paired subset(see Fig. 1). The dependent variable was the average yearly economic cost $\left(\log _{10^{-}}\right.$ transformed) and the independent variables included a binary PA status factor (i.e. whether the cost pertains to a PA or Non-PA) and its interactions with the following descriptors: continent, taxonomic group, environment, impacted sector and type of cost (Table 1). This allowed us to assess the differences in the average yearly economic cost between PAs and non-PAs for these descriptors. Prior to performing this analysis, we assessed that none of the predictors were highly intercorrelated, suggesting the absence of multicollinearity (Pearson's $r<0.65$; Supplementary Material 4), Therefore, all predictors were retained in the analysis. We used the adjusted $\mathrm{R}^{2}$ to assess the percentage of mean annualized economic cost variation that is explained by the models. Significant interactions were assessed using the drop 1 function to obtain Type III sum of squares ANOVA containing p-values from an F-test. Residuals were analyzed using the simulateResiduals function of the 'DHARMa' package version 0.3.3 (Hartig 2020) and they satisfied all classical regression assumptions. Additionally, when an interaction factor showed a significant effect, we carried out a post-hoc Wilcoxon Signed Rank test with Holm correction in order to determine which categories were significantly different between protected and non-protected areas.

\section{Factors affecting costs of invasive alien species across protected areas}

To assess which variables could affect the economic costs of IAS within PAs, we performed a multiple linear regression using the data corresponding to the "protected area WDPA subset" (see Fig. 1). We used the $\log _{10}$-transformed average yearly economic costs as the dependent variable. We added $P A$ designation, year of PA designation, PA surface area, human development index, continent, taxonomic group, environment, and type of cost as independent variables. Impacted sector was not considered in this model because of unbalanced sample size among the categories (of the 7 impacted sector categories, authorities and stakeholders comprised $92 \%$ of the entries). We first excluded incomplete cases (i.e. rows with missing values), and we assessed the correlation among predictors (all predictors were retained in the analysis; Pearson's $r<0.65$; Supplementary Material 5). We ran a multiple linear regression and similar to the previous model, we produced the output using the drop 1 function, assessed residuals (which satisfied all regression assumptions) and tested for differences among categories for the significant factors using the Wilcoxon signed-rank test with Holm corrected $p$-values.

For each test, when reporting the statistical results of average economic costs, we provide medians and standard deviation because these estimates fairly approximate the mean values of our $\log _{10}$-transformed data and avoid skewed distributions due to cost outliers. All figures were produced in R using ggplot2 (Wickham 2016).

\section{Results}

What are the overall economic costs of invasive species in protected areas? 
The total reported economic costs in PAs amounted to $\$ 22.13$ billion over the last 44 years (1976-2020). Observed costs amounted to $\$ 802.47$ million between $1980-2020$ and averaged $\$ 19.56$ million annually since the 1980s, while potential costs amounted to $\$ 21.18$ billion and averaged $\$ 516.59$ million over the same period (Supplementary Material 6). Both types of costs were generally characterised by an increase over time, with potential costs increasing markedly between 1995 and 2000. Observed costs exhibited a gradual increase over time, with reductions in recent years likely due to time lags in cost reporting. The number of entries for both types of costs has been increasing over time, and especially those of observed costs.

PA costs were not distributed homogeneously across continents (Fig. 2a). In particular, most of the observed costs were reported for Africa (27\%), followed by South America (19\%), Tropical Asia (16\%), Australasia (15\%), Europe (8\%), North America (7\%), Temperate Asia (5\%), Pacific Islands (2\%) and Antarctica (1\%). However, this pattern is quite different when taking into account both observed and potential costs: more costs were incurred by PAs located in Australasia (59\%), followed by Europe (35\%) and distantly followed by PAs located in Africa (4\%), South America (1\%), and North America (0.5\%). Potential costs were not reported for Antarctica, the Pacific Islands, or Tropical and Temperate Asia. Moreover, by scrutinizing the number of entries for each continent, we found that most cost occurrences were reported for PAs in Europe and Africa (1,247 cost entries independently), followed by South America (519 entries) while the rest of continents reported less than 300 entries.

In terms of the types of IAS cost incurred by PAs, the majority of the observed costs were characterised as management costs (i.e. "pre-invasion", "post-invasion", "knowledge and funding" and "mixed management costs" were equivalent to $\$ 556.71$ million), thereby dominating observed damage costs (i.e. "damage" and "mixed management and damage" costs were equivalent to \$238.86 million) (Fig. 2b). Within management costs, "post-invasion" management (i.e. control, eradication, harvesting, management and monitoring) represented the highest proportion of observed costs caused by IAS. In terms of potential costs, damage costs (95\%) constituted the majority (i.e. "damage" and "mixed management and damage") whilst management costs represented only $5 \%$.

Governmental services and/or official organizations such as conservation agencies, forest services, or associations that allocate funding for the management of biological invasions ("authorities and stakeholders") incurred the highest observed costs (\$464.27 million; 58\%) compared to other sectors (Fig. 2b). This sector accounted for more than $80 \%$ of all types of management costs, except for "mixed management", where it represents $34 \%$ of costs. The "agriculture" and "public and social welfare" sectors sustained the most "damage" and "mixed damage and management" costs respectively ( $62 \%$ and $89 \%$, respectively). The "environment" and "public and social welfare" sectors accounted for $95 \%$ of all potential costs generated by IAS in PAs (64\% and $31 \%$, respectively) and close to $100 \%$ of damage costs ( $67 \%$ and $33 \%$, respectively). "Authorities and stakeholders" accounted for the majority of potential management costs ( $82 \%$ to $100 \%$, respectively). 
Plants dominated the Protected area subset with $70 \%$ of the observed cost entries and $80 \%$ of the potential cost entries (Fig. 3). However, observed costs for animals were three times larger than for plants (\$550 and 170 million, respectively) and potential animal costs were 1.5 times larger than for plants (\$13 and 8 billion, respectively). Magnoliopsida (61\% of observed plant costs and $64 \%$ of observed plant entries), Mammalia (47\% of observed animal costs and $50 \%$ of observed animal entries) and Insecta ( $46 \%$ of observed animal costs and; $10 \%$ of observed animal entries) greatly influenced plant and animal costs, as well as the number of entries.

\section{How do costs compare between non-protected and protected areas?}

Overall, the average observed economic costs caused by IAS differed significantly between non-PAs and PAs, with higher average yearly observed costs incurred in PAs $(\$ 13,095.75 \pm \$ 568,459.90 ;$ median \pm SD) in comparison to non-PAs (\$3,473.11 $\pm \$ 176.54$ million) (Fig. 4a). In relation to descriptors that potentially drive these differences, only the interactions of protection status with the environment and with the continent in which the species costs incurred significantly influenced observed costs (Supplementary Material 7). The percentage of variance explained by the cost model was $27.03 \%$ (adjusted $\mathrm{R}^{2}$ ).

In terms of the type of environments and land protection status, only terrestrial ecosystems displayed a significant effect with higher mean costs incurred in PAs $(\$ 13,346.13 \pm \$ 658,553.70)$ compared with nonPAs (\$2,818.65 $\pm \$ 205.40$ million) (Fig. 4b). Additionally, costs in terrestrial ecosystems accounted for $72 \%$ of reported cost entries across all environments.

Examining the expenditure for IAS management across continents and land protection status (Fig. 4c), we found that the mean costs incurred by non-PAs in Africa (\$99,617.04 $\pm \$ 2.80$ million) and South America $(\$ 31,440.13 \pm \$ 232,870.28)$ are significantly higher compared to costs incurred in PAs $(\$ 20,620.97 \pm \$ 189,979.35$ for African PAs; $\$ 1,860.68 \pm$ and $\$ 76,476.52$ for South American PAs). However in Europe, mean costs are significantly higher inside PAs $(\$ 7,973.45 \pm \$ 575,142.76)$ compared to costs incurred in non-PAs (\$987.39 $\pm \$ 185,394.24)$.

The top five costliest species incurring costs across terrestrial environments in PAs comprised animal taxa and these are mostly mammals followed by two insects (Fig. 4d). The costliest species incurring costs in African PAs included plants (particularly terrestrial shrubs and a forb); PAs in South America are also affected primarily by plants (particularly terrestrial trees and a shrub) with the exception of the European rabbit (Oryctolagus cuniculus), which is also listed among the most costly species (Fig. 4e). The costliest species in European PAs include both animals and plants, and in contrast to Africa and South America, these mainly comprise semi-aquatic and aquatic species with the exception of the Asian hornet (Vespa velutina).

\section{Which factors influence invasive alien species costs across protected areas?}


Factors driving the average yearly observed costs across PAs include six descriptors (three cost descriptors and three PA descriptors): year of designation, protected area size, human development index, type of environment, continent and taxonomic group,Supplementary Material 8). These descriptors explained $20.5 \%$ (adjusted $\mathrm{R}^{2}$ ) of the variance.

Although year of designation and protected area size showed a significant effect in the model as covariates, when examined on their own, there were no significant differences across the categories (Fig. $5 a, b)$. Nevertheless, we see that areas classified as PAs in the 2000s and PAs occupying $500-5000 \mathrm{~km}^{2}$ incurred higher mean costs. Further, we found a significant positive relationship between the average costs of IAS and the human development index (i.e. socio-economic wellbeing of a country) (Fig. 5c).

When taking a closer look at the type of environment incurring costs within PAs, "diverse/unspecified" (\$ $46,167.60 \pm \$ 626,494.17)$, "terrestrial" (\$15,793.58 $\pm \$ 967,180.32)$ and "semi-aquatic" (\$14,045.07 \pm $\$ 10.32$ million) environments sustained significantly higher mean costs compared to costs incurred in "aquatic" environments of PAs (\$2098.01 $\pm \$ 85,976.39)$ (Fig. 5d). Moreover, costs in terrestrial environments within PAs contained the majority of reported costs entries (65\%) but incurred only $20 \%$ of the mean costs.

The Pacific islands incurred the majority of the average yearly economic costs $(74 \%$ of mean cost estimates), followed by North America (10\%), Antarctica (8\%), Australasia (3\%), Temperate Asia (2\%), Africa (2\%), South America (0.5\%), and Europe (0.5\%) (Fig. 5e). Despite the highest mean costs reported in PAs of Pacific islands ( $\$ 1,06$ million $\pm \$ 1.38$ million), the reported number of cost entries are the lowest ( $2 \%$ of all cost entries). On the contrary, European PAs incurred the lowest costs $(\$ 6,825.76 \pm$ $\$ 568,731.70)$ despite having the highest number of reported costs ( $46 \%$ of all cost entries). Lastly, the effect of continent among covariates is context-dependent, suggesting that the overall effects of spatial distribution on the magnitude of costs is significantly affected by IAS.

Average yearlycosts in PAs were similar for taxa classified as "diverse/unspecified" (\$65,544.56 $\$ \$ 1.35$ million), "vertebrates" (\$36,116.43 $\pm \$ 3.13$ million) and "invertebrates" (\$23,260.56 $\pm \$ 11.39$ million) (Fig. 5f). However, the average costs for these two groups significantly differed from average "plant" costs $(\$ 7,204.72 \pm \$ 115,963.00)$. Although more costs were reported for plants (53\% of cost entries), surprisingly, they incurred the lowest expenditure (5\% of mean costs).

\section{What insights were gained from PA managers?}

The survey was filled by only six PA managers out of the 44 contacted: Ria De Villaviciosa Nature Reserve and La Palma Biosphere Reserve (Spain), Kruger National Park (South Africa), Ogasawara National Park (Japan), and Japoon National Park and Mulligans Flat (Australia). Managers generally perceived IAS as the most threatening factor affecting conservation in their PA, mainly due to their impacts on native species, native ecosystems and aesthetics (Supplementary Material 9). In four of these PAs, managers perceived the costs of managing IAS in their PAs as higher than those registered in InvaCost, with the exception of one PA manager who thought that management costs are actually lower than those 
reported. Half of the managers considered the budgets available for managing IAS to be insufficient, especially those available for preventing new invasions. They identified human capacity, funding and equipment as the main limitations of invasive species management in their PAs. Managers also reported that invasive plant management is generally prioritized over other invasive taxa. Further, they often prioritized the management of IAS which cause the highest impacts, followed by those with the smallest distribution and those for which reliable methods are available for controlling the spread. Although most managers mentioned that they are not mandated to collect data on the actions and costs of managing IAS in their PAs, they believe that it is still necessary to do so. However, not all of them consider it necessary to make this data publicly available, and those that do cannot always do so due to a lack of time and/or technical capacity.

\section{Discussion}

\section{Where do we stand?}

This study provides the first comprehensive compilation and analysis of reported costs of biological invasions in PAs around the world: which amounts to $\$ 22.13$ billion over the last 44 years (1976-2020). The highest observed costs from invasions in PAs were found in Africa, and the highest number of reported entries was in Europe. These costs were caused primarily by vertebrates and to a lesser extent by flowering plants (though more costs were reported for plants). Most costs were incurred post-invasion and largely affected PA authorities and stakeholders. We also found that, in general, mean invasionrelated costs in PAs were higher compared to paired non-PAs. Further, vertebrates (particularly mammals) and invertebrates (particularly insects) were found to be the most expensive to manage in terrestrial environments. Additionally, we found that the mean costs of IAS depended on a country's human development index, the type of environment, continent, and taxonomic groups. Further, research effort, as reflected by the number of cost entries, was inversely correlated with the magnitude of observed costs. Additionally, according to managers' views, although IAS are perceived as a major threat, several limitations (e.g. time, budgets and technical capacity) reportedly impede effective conservation.

\section{Economic cost reporting in protected areas}

The reporting of economic costs of invasions in PAs has not increased equivalently to increases in reporting of costs observed more broadly. Sporadic cost reporting for PAs, as evidenced by the data and the literature points towards a lack of reporting structures, mechanisms and/or incentives for logging invasion costs, and/or methodological expertise for monetary quantifications (Diagne et al. 2020a; Robertson et al., 2020). Moreover, the results of our survey suggest that these data might exist but, due to a lack of human capacity, time or interest, they are not often made publicly available. Nevertheless, costs have steadily increased over time in PAs, both in terms of magnitude and the numbers of reported cost entries. A vast majority of costs in PAs emanate from predictions, models or simulations (i.e. "potential" costs in the database) and therefore further work is needed, wherever possible, to capture and report 
invasion costs on the ground. Lastly, the fact that our dataset shows potential costs were reported 15 years after observed costs, likely reflects recent advancements in modelling techniques.

\section{Taxonomic bias in economic costs and scientific studies}

Our study, like many others in invasion science (Pysek et al. 2008), reflects a strong taxonomic bias, in terms of economic costs, research effort and taxonomic awareness (Rico-Sanchez et al. 2020). Invasive predatory mammals are largely known to have the most devastating effects on biodiversity worldwide (Doherty et al. 2016; Liu et al. 2020). This aligns with findings in this study that mammals are the most costly to manage in PAs, and is similar to patterns within PAs of other countries (see for example RicoSánchez et al. 2021 in México or Ballesteros-Mejia et al. 2021 in Ecuador). In particular, wild boar (Sus scrofa) and rats (Rattus spp.) incurred the highest overall mean costs. Further, in line with Pyšek et al. (2008), who suggest that invertebrates are abundantly studied, we found that insects had the second highest reported costs in PAs. These costs were mostly driven by the mango pulp weevil (Sternochetus frigidus), followed by the Asian tiger mosquito (Aedes albopictus). Mango pulp weevil costs were all from the Palawan game refuge and bird sanctuary. The high investment in controlling this weevil is likely due to mango being the third most important fruit crop in the Philippines. By feeding on the fruit, the weevil destroys its production and marketability (McKinley et al. 2012). Mosquitoes pose a significant threat to humans, as they can serve as vectors of pathogens which can lead to the spread of diseases (Schaffner et al. 2013). In this study, the high expenses for the Asian tiger mosquito were incurred in the Réunion National Park, which is not surprising since this species has become a major human health concern across the island of Réunion in the Western Indian Ocean (Latreille et al. 2019).

Although we found that plants are managed more often in PAs (as shown in both the Protected Area and WDPA subsets), their reported observed costs are substantially lower than those of mammals. Flowering plants accrued the highest reported expenses, with most costs associated with the aquatic plant, Ludwigia peploides, and trees belonging to the genera Acacia, Pinus and Hakea. Expenses for $L$. peploides were all incurred in French PAs and this is likely due to their high invasion success and associated impacts in France (Dandelot et al. 2008). Globally, invasive trees have significant (and growing) impacts on the environment and the economy (Richardson and Rejmánek 2011; Hirsch et al. 2017), hence it is not surprising that trees incur the second highest costs in this group. Potential reasons for the higher number of reported cost entries include the fact that invasive alien plants are generally studied more than other taxonomic groups (Pysek et al. 2008; Warren II et al. 2017) and also because they can successfully dominate many ecosystems (Pyšek et al. 2017). However, despite this bias, plants were found to incur the lowest monetary costs. This may be attributed to the difficulty and high management costs associated with plant control and/or eradication (Gardener et al. 2010). For example, species with the ability to form persistent seed banks are complex to control and require regular follow ups in order to effectively deplete their seed banks (Gioria et al. 2012; Strydom et al. 2017). Such species require high control effort (e.g. long-term monitoring and management), and/or their failed control attempts may have not been reported, potentially distorting the true magnitude of damage costs and management expenditure (Zenni and Nuñez 2013). This highlights the importance of persevering with 
control efforts, as well as creating awareness of the importance of reporting all invasion costs. Lastly, looking at the type of costs associated with these species, it is apparent that the prevalent management focus on mammals (pigs and rats), insects (mango weevil), and plants (water primrose) in PAs is mostly a result of their associated damage costs (i.e. damage was the second highest type of observed cost reported after post-invasion management).

\section{Geographical bias in economic costs and scientific studies}

IAS research in PAs has shown to be geographically biased towards the Americas and Pacific islands while less frequently studied regions include Europe, Africa and Asia (Hulme et al. 2014). However, with regard to economic studies, this pattern does not hold true. We show that observed costs are more frequently reported in regions including Europe, followed by Africa and South America while cost reporting in the Pacific islands are considerably lagging. European efforts can be attributed to two factors. Firstly, Europe contains the most number of PAs in the world $(n=158,450$; UNEP-WCMC and IUCN 2019). As such, these cost patterns are likely an artefact of the available literature. Alternatively, the higher number of PAs in Europe may provide more opportunities to study invasions across different landforms, islands, peninsulas and climates. Secondly, the implementation of the European Union's Natura 2000 PA network, the largest coordinated network of PAs in the world, possibly plays a major role in shaping this pattern since part of the action plan is to stimulate monitoring and reporting across the networks (European Environmental Agency 2012). Accordingly, the increase in entries in our database since the early 1990s coincides with establishment of the Natura 2000 PA network.

Despite the higher research effort in European PAs, African and South American PAs incur substantially higher total observed costs. The majority of recorded costs in Africa have been accrued in South Africa (i.e. Western Cape Province and Kruger National Park), a leader in invasion biology research with a long history of conservation efforts (van Wilgen et al. 2020). The substantial investment in IAS management in the Western Cape can be attributed to South Africa's Natural Resources Management Programme (formerly the Working for Water programme) whose purpose is to remove invasive plants from catchments to increase water yields and restore biodiversity, as well as create jobs (van Wilgen et al. 2010). Moreover, research effort in this region has also been driven by the Centre of Excellence for Invasion Biology in South Africa (Richardson et al. 2020). Kruger National Park is burdened by the highest number of IAS in South African National Parks and control efforts have taken place since the 1950s (Foxcroft and Freitag-Ronaldson 2007; Foxcroft et al. 2017b). In South American PAs, most research investment, as reflected by the high observed total costs, largely occurred in the Galápagos Islands, Ecuador, where IAS are the biggest biodiversity threat (Trueman et al. 2010). Consequently, the high economic costs reported on these islands may be the result of intensive management activities (Gardener et al. 2010, 2013), as well as the importance of the Galapagos Islands to both biology and tourism (Ballesteros-Mejia et al. in press).

\section{Costs drivers between protected and non-protected areas}


There is a notable difference in the total observed mean costs of IAS accrued inside (\$74.61 million) and outside (\$6.18 billion) PA environments. This can be attributed to several factors. Firstly, PAs only cover up to $15 \%$ of the planet's land surface. As such, even though a significantly high amount of money is spent inside PAs on average, we suggest that higher investments should be considered for IAS in nonPAs. Land use and other impacts outside PAs significantly influence species and ecosystems within PAs (Foxcroft et al. 2011; Liu et al. 2020), and therefore managing IAS outside PA networks is necessary to ensure effective conservation within PA networks. Nevertheless, although we matched PA and non-PA costs according to their environment, taxonomic group and continent, we could not verify whether these non-PAs and PAs are ecologically connected. Secondly, in comparison to non-PAs, PAs are species rich (Gray et al. 2016) and should comply with the long standing hypothesis of biotic resistance (i.e. high native species richness reduces the success of invading species). Consequently this potential "Iower invasion success" may explain the comparatively lower total costs incurred inside PAs. Third, PAs are likely to be subject to less anthropogenic activity with less human-made infrastructure or economic activities that can be damaged or degraded by invasions compared to non-PAs. This is either because PAs have been established in relatively pristine areas or because their protection status inherently limits potential environmentally-detrimental economic activities. Non-PAs may therefore be more likely to incur resource damage or loss costs, whereas PAs are more likely to incur management costs. Lastly, given the inadequate funding available to PAs (Shackleton et al. 2020b), managing invasions can be a challenge, as also evidenced by the response of PA managers in our survey.

Our results show that the HDI markedly influences the economic costs of IAS in PAs. This significant correlation with economic costs but a low R-squared value suggests that although HDI is a significant driver, it does not explain much of the variability in the cost estimates. Even so, this positive effect between the degree of wealth and conservation decisions is likely due to developed countries being more aware, having the ability to better document damage costs, and most importantly having more means to manage IAS (Nuñez and Pauchard 2010). In addition, for most developing countries, the primary goal of economic growth does not always go hand in hand with conservation goals. Consequently, major environmental problems, such as biological invasions, continue to be a challenge in countries with fragile economies (Early et al. 2016). Further, invaders from terrestrial and semi-aquatic environments have the highest costs while aquatic taxa have the lowest. The high costs associated with terrestrial species are likely driven by vertebrates (particularly mammals) and invertebrates (particularly insects) which were found to be the most costly in this environment, while the high semi-aquatic costs likely reflect taxa such as mosquitoes, which cause high health costs and have an aquatic life stage. The low costs for aquatic species is likely due to the cryptic nature of submerged environments and the respective difficulty in managing their invasive populations (e.g. aquatic macrophytes). Further, the challenges and high costs of monitoring in aquatic systems often result in identifying aquatic IAS at an advanced invasion stage, which may result in a limited understanding of their costs.

\section{Overcoming management challenges in protected areas}


The control and eradication of IAS in PAs are time- and resource-consuming, and prioritization schemes are necessary in light of limited available budgets for conservation (Ziller et al. 2020). Information on the costs of IAS can serve as valuable input to priority-setting schemes aimed at managing biological invasions in PAs. This becomes even more important given that most countries have a limited capacity to effectively respond to invasions (McCarthy et al. 2012; Early et al. 2016; Faulkner et al. 2020), and decisions about resource allocation for biosecurity, control and post-invasion management are thus often made on an ad hoc basis (Epanchin-Niell 2017; Liebhold and Kean 2019; Kourantidou and Kaiser 2021). Knowledge of IAS economic costs is key to help PA managers invest in efforts that optimize large scale positive results at the lowest possible cost (Gallardo and Aldridge 2013).

Lower expenditure on pre-invasion than post-invasion management suggests that management strategies are more reactive than proactive and indicates that management costs are much higher than prevention costs. This pattern may extend beyond PAs, as this type of reactive management has also been noted in non-PAs of Central and South America (Heringer et al. in press). Further, the dominance of post-invasion management expenditure points to the need for more preventative measures, such as biosecurity, to curtail the increased expenses associated with late-stage invasion management (see for example, Leung et al. 2002). Given that preserving biodiversity is one of the main goals of PAs (although in some cases goals are combined with others depending on the management category of the PA; see https://www.iucn.org/theme/protected-areas/about/protected-area-categories), pre-invasion management is seen as essential to avoiding the myriad impacts of IAS on native species and ecosystems.

Responses from our survey show that managers understand the importance of preventative measures. This is reflected through managers' efforts to control species before they are widespread and abundant, though this approach is partly attributed to a lack of resources to face higher costs expected once IAS become widespread. Further, as the PAs selected for the survey are either national parks (which protect natural biodiversity and large-scale ecological processes) or reserves (where human visitation, use and impacts are strictly controlled), it is expected that they correspond to PAs where biodiversity conservation is a top priority for management. Therefore, we can expect that if time, budgets and capacity impede IAS management in these PAs, it is likely that the big picture of PA conservation might be even worse.

\section{Serious cost underestimation in protected areas}

While biological invasions continue to increase, the efficacy of PAs in conserving biodiversity remains limited (Rodrigues et al. 2004; Liu et al. 2020). Generally, the effectiveness of management can differ markedly across PAs, with just $22 \%$ of PAs recognized as having "sound management" (Leverington et al. 2010). Ineffective management of these so-called "paper parks" (i.e. parks in name only which provide little or no protection) mainly stems from a lack of investment. This is the case of many PAs from developing countries due to chronic financial deficit (James et al. 1999; Wilkie et al. 2001; Gill et al. 2017; Lindsey et al. 2018). Balmford et al. (2002) suggested yearly investments of approximately $\$ 45$ billion (over 30 years) to efficiently maintain an expanded network of tropical PAs covering $15 \%$ of terrestrial and 
$30 \%$ of marine ecosystems; a study by McCarthy et al. (2012) put forward that $\$ 76$ billion per year is needed to conserve terrestrial PAs globally; Balmford et al. (2004) proposed that it would cost \$5-19 billion per year to conserve $20-30 \%$ of marine ecosystems globally; and finally, Lindsey et al. (2018) suggested that $\$ 1-2$ billion per year are required to conserve African PAs with lions. PAs in developing countries generally receive significantly less funding than that required for basic conservation management (James et al. 1999; Bruner et al. 2004). Our results reveal that although PAs in continents such as Africa and South America incurred higher costs, they do not equivalently invest in IAS management. More importantly, this suggests the need for prioritizing investments in highly impacted PAs of the world. Further, the taxa highlighted in this paper, as well as, in the number of reported entries and the inadequate funding suggested by the PA managers indicates that current reporting of IAS costs in PAs is greatly underestimated.

PAs serve as the backbone of global conservation and biological invasions are a key driver of change in PAs (Foxcroft et al. 2017a; Shackleton et al. 2020a,b). A variety of factors are responsible for the economic costs incurred by PAs, many of which have not been captured in this study, either due to data deficiency and/or because other key factors have not been assessed (e.g. time lags or species richness). Moreover, we may lack knowledge for under-studied regions or taxa. Nevertheless, our study shows that many IAS have already caused significant management and damage costs across all environments and continents. If not managed resourcefully, their impacts can only be expected to intensify. Globally, the number of IAS are expected to increase as more species are introduced via global trade and more invasions are discovered as a result of invasion debt (Essl et al. 2011; Seebens et al. 2017, 2020). As such, we strongly encourage comprehensive economic estimations and reporting of current (observed) and future (potential) management costs across PAs in order to improve IAS management. This will provide an opportunity to maximize return on conservation investments which will have a significant impact on biodiversity outcomes in PAs.

\section{Declarations}

\section{Funding}

The authors acknowledge the French National Research Agency (ANR-14-CE02-0021) and the BNPParibas Foundation Climate Initiative for funding the InvaCost project that allowed the construction of the InvaCost database. The present work was conducted following a workshop funded by the AXA Research Fund Chair of Invasion Biology and is part of the AlienScenarios project funded by BiodivERsA and Belmont-Forum call 2018 on biodiversity scenarios. DM and AN are funded by grant no. 18-18495S, EXPRO grant 19-28807X (Czech Science Foundation) and long-term research development project RVO 67985939 (Czech Academy of Sciences). RNC acknowledges funding from the Alexander von Humboldt

Foundation. EA's contract comes from the AXA Research Fund Chair of Invasion Biology of University Paris Saclay. CD is funded by the BiodivERsA-Belmont Forum Project "Alien Scenarios" (BMBF/PT DLR 01LC1807C). GH is supported by Coordenação de Aperfeiçoamento de Pessoal de Nível Superior - Brasil (Capes). DR is funded by the BiodivERsA 'ASICS project (ANR-20-EBI5-0004, BiodivClim call 2019-2020), 
the French Polar Institute Paul-Emile Victor (Project IPEV 136 'SUBANTECO'), and the long-term research network on biodiversity in Antarctic and sub-Antarctic ecosystems (Zone Atelier InEE-CNRS Antarctique et Terres Australes). JFL's travel funding to attend the Invacost workshop was provided by the Auburn University School of Forestry and Wildlife Sciences.

\section{Conflict of interest}

The authors declare that there is no conflict of interest.

\section{Availability of data and material}

All data used are available in the Supplementary Material (ESM_2).

\section{Code availability}

Not available

\section{Ethics approval}

Not applicable

\section{Consent to participate}

Not applicable

\section{Consent for publication}

All authors have read and approved the submitted version of the manuscript.

\section{References}

Angulo E, Diagne C, Ballesteros-Mejia L, et al (in press) Non-English languages enrich scientific knowledge: the example of economic costs of biological invasions. Science of the Total Environment.

Bailey SA, Brown L, Campbell ML, et al (2020) Trends in the detection of aquatic non-indigenous species across global marine, estuarine and freshwater ecosystems: A 50-year perspective. Divers Distrib 26:1780-1797. https://doi.org/https://doi.org/10.1111/ddi.13167

Balmford A, Bruner A, Cooper P, et al (2002) Economic reasons for conserving wild nature. Science 297:950-953

Balmford A, Gravestock P, Hockley N, et al (2004) The worldwide costs of marine protected areas. Proc Natl Acad Sci USA 101:9694-9697. https://doi.org/10.1073/pnas.0403239101

Ballesteros-Mejia L, Angulo E, Diagne C , Cooke B, Nuñez MA, Courchamp F (in press) Economic costs of biological invasions in Ecuador: the importance of the Galapagos Islands. NeoBiota 
Bradshaw CJA, Leroy B, Bellard C, et al (2016) Massive yet grossly underestimated global costs of invasive insects. Nat Commun 7:12986. https://doi.org/10.1038/ncomms12986

Brummitt RK (2001) World Geographical Scheme for Recording Plant Distributions, 2nd edn. Hunt Institute for Botanical Documentation, Carnegie-Mellon University, Pittsburgh, Penna

Bruner AG, Gullison RE, Balmford A (2004) Financial costs and shortfalls of managing and expanding protected-area systems in developing countries. Bioscience 54:1119-1126.

https://doi.org/10.1641/0006-3568(2004)054[1119:fcasom]2.0.co;2

Butchart SHM, Walpole M, Collen B, et al (2010) Global Biodiversity: Indicators of Recent Declines. Science 328:1164-1168. https://doi.org/10.1126/science.1187512

Chape S, Harrison J, Spalding M, Lysenko I (2005) Measuring the extent and effectiveness of protected areas as an indicator for meeting global biodiversity targets. Phil. Trans. R. Soc. B 360:443-455. https://doi.org/doi:10.1098/rstb.2004.1592

Charles H, Dukes JS (2008) Impacts of Invasive Species on Ecosystem Services. In: Nentwig W (ed) Biological Invasions. Springer, Berlin, Heidelberg

Colautti RI, Bailey SA, van Overdijk CDA, et al (2006) Characterised and projected costs of nonindigenous species in Canada. Biol Invasions 8:45-59

Conn DB (2014) Aquatic invasive species and emerging infectious disease threats: A One Health perspective. Aquat Invasions 9:38-390

Crystal-Ornelas R, Hudgins EJ, Cuthbert RN, et al (in press) Economic costs of biological invasions within North America. NeoBiota

Cuthbert RN, Pattison Z, Taylor NG, et al (in press) Global economic costs of aquatic invasive alien species. Sci Total Environ

Dana ED, Jeschke JM, García-de-Lomas J (2014) Decision tools for managing biological invasions: existing biases and future needs. Oryx 48:56-63

Dandelot S, Robles C, Pech N, et al (2008) Allelopathic potential of two invasive alien Ludwigia spp. Aquat Bot 88:311-316

Daněk J, Vačkáŕ D, Krkoška Lorencová E (2017) Value of ecosystem services in Protected Landscape Areas in the Czech Republic. Beskydy 10:99-112

Diagne C, Catford JA, Essl F, Nuñez MA, Courchamp F (2020a) What are the economic costs of biological invasions? A complex topic requiring international and interdisciplinary expertise. NeoBiota 63: 25-37. https://doi.org/10.3897/neobiota.63.55260 
Diagne C, Leroy B, Gozlan RE, et al (2020b) InvaCost, a public database of the economic costs of biological invasions worldwide. Sci Data 7:277. https://doi.org/10.1038/s41597-020-00586-z

Diagne $\mathrm{C}$, Leroy B, Vaissière A-C, et al (in press-a) High and rising economic costs of biological invasions worldwide. Nature.

Diagne C, Turbelin A, Moodley D, et al (in press-b) The economic costs of biological invasions in Africa: a growing but neglected threat? NeoBiota.

Early R, Bradley BA, Dukes JS, et al (2016) Global threats from invasive alien species in the twenty-first century and national response capacities. Nat Commun 7:12485. https://doi.org/10.1038/ncomms12485

Ehrenfeld JG (2010) Ecosystem consequences of biological invasions. Annu Rev Ecol Evol Syst 41:59-80

Ellstrand NC, Schierenbeck KA (2000) Hybridization as a stimulus for the evolution of invasiveness in plants? Proc Natl Acad Sci USA 97:7043-7050

Engeman RM, Laborde JE, Constantin BU, et al (2010) The economic impacts to commercial farms from invasive monkeys in Puerto Rico. Crop Prot 29:401-405

Epanchin-Niell RS (2017) Economics of invasive species policy and management. Biol Invasions 19:3333-3354. https://doi.org/10.1007/s10530-017-1406-4

Essl F, Dullinger S, Rabitsch W, et al (2011) Socioeconomic legacy yields an invasion debt. Proc Natl Acad Sci 108:203 LP - 207. https://doi.org/10.1073/pnas.1011728108

European Environmental Agency (2012) Protected areas in Europe: an overview. EEA Report № 5/2012. EU, Luxembourg

Faulkner KT, Robertson MP, Wilson JRU (2020) Stronger regional biosecurity is essential to prevent hundreds of harmful biological invasions. Glob Chang Biol 26:2449-2462. https://doi.org/10.1111/gcb.15006

Foxcroft L, Freitag-Ronaldson S (2007) Seven decades of institutional learning: Managing alien plant invasions in the Kruger National Park, South Africa. Oryx 41:160-167.

https://doi.org/doi:10.1017/S0030605307001871

Foxcroft LC, Jarošík V, Pyšek P, et al (2011) Protected-area boundaries as filters of plant invasions. Conserv Biol 25:400-405

Foxcroft LC, Pyšek P, Richardson DM, et al (2017a) Plant invasion science in protected areas: progress and priorities. Biol Invasions 19:1353-1378. https://doi.org/10.1007/s10530-016-1367-z

Foxcroft LC, Pyšek P, Richardson DM, Genovesi P (2013) Plant invasions in protected areas: Patterns, problems and challenges 
Foxcroft LC, Van Wilgen NJ, Baard JA, Cole NS (2017b) Biological invasions in South African National Parks. Bothalia 47:a2158. https://doi.org/10.4102/abc.v47i2.2158

Gaertner M, Biggs R, Te Beest M, et al (2014) Invasive plants as drivers of regime shifts: identifying highpriority invaders that alter feedback relationships. Divers Distrib 20:733-744.

https://doi.org/10.1111/ddi.12182

Gallardo B, Aldridge DC (2013) Priority setting for invasive species management: risk assessment of Ponto-Caspian invasive species into Great Britain. Ecol Appl 23:352-364

Gallardo B, Aldridge DC, González-Moreno P, et al (2017) Protected areas offer refuge from invasive species spreading under climate change. Glob Chang Biol 23:5331-5343.

https://doi.org/https://doi.org/10.1111/gcb.13798

Gantchoff MG, Wilton CM, Belant JL (2018) Factors influencing exotic species richness in Argentina's national parks. PeerJ 6:e5514. https://doi.org/10.7717/peerj.5514

Gardener MR, Atkinson R, Rentería JL (2010) Eradications and People: Lessons from the Plant Eradication Program in Galapagos. Restor Ecol 18:20-29. https://doi.org/https://doi.org/10.1111/j.1526100X.2009.00614.x

Gardener MR, Trueman M, Buddenhagen C, et al (2013) A Pragmatic Approach to the Management of Plant Invasions in Galapagos BT - Plant Invasions in Protected Areas: Patterns, Problems and Challenges. In: Foxcroft LC, Pyšek P, Richardson DM, Genovesi P (eds) Plant Invasions in Protected Areas. Springer Netherlands, Dordrecht, pp 349-374

Geldmann J, Barnes M, Coad L, et al (2013) Effectiveness of terrestrial protected areas in reducing habitat loss and population declines. Biol Conserv 161:230-238

Gill DA, Mascia MB, Ahmadia GN, et al (2017) Capacity shortfalls hinder the performance of marine protected areas globally. Nature 543:665-669. https://doi.org/10.1038/nature21708

Gioria M, Pyšek P, Moravcová L (2012) Soil seed bank in plant invasions: promoting species invasiveness and long-term impact on plant community dynamics. Preslia 84:327-350

Gray CL, Hill SLL, Newbold T, et al (2016) Local biodiversity is higher inside than outside terrestrial protected areas worldwide. Nat Commun 7:12306. https://doi.org/10.1038/ncomms12306

Hartig F (2020) DHARMa: Residual diagnostics for hierarchical (multi-level/mixed) regression models. R package version 0.3.3.0

Haubrock PJ, Cuthbert RN, Ricciardi T, et al (in this issue) Massive global economic costs of invasive macrofouling freshwater bivalves. Biol Invasions 
Haubrock PJ, Novoa A, Turbelin AJ, et al (in press) Costs of invasive species in Europe. Neobiota

Hejda M, Pyšek P, Jarosik V (2009) Impact of invasive plants on the species richness, diversity and composition of invaded communities. J Ecol 97:393-403

Heringer G, Almeida TE, Dittrich VA de O, Salino A (2020) Assessing the effectiveness of protected areas for the conservation of ferns and lycophytes in the Brazilian state of Minas Gerais. J Nat Conserv 53:125775. https://doi.org/10.1016/j.jnc.2019.125775

Heringer G, Angulo E, Ballesteros-Mejia L, et al (in press) The economic costs of biological invasions in Central and South America: a first regional assessment. Neobiota

Hirsch H, Richardson DM, Le Roux JJ (2017) Introduction to the special issue: Tree invasions: towards a better understanding of their complex evolutionary dynamics. AoB Plants 9:plx014. https://doi.org/https://doi.org/10.1093/aobpla/plx014

Hoffmann BD, Broadhurst LM (2016) The economic cost of managing invasive species in Australia. NeoBiota 31:1-18. https://doi.org/10.3897/neobiota.31.6960

Hulme PE (2014) Invasive species challenge the global response to emerging diseases. Trends Parasitol $30: 267-270$

Hulme PE, Pyšek P, Pergl J, et al (2014) Greater focus needed on alien plant impacts in protected areas. Conserv Lett 7:459-466. https://doi.org/10.1111/conl.12061

lacarella JC, Burke L, Davidson IC, et al (2020) Unwanted networks: vessel traffic heightens the risk of invasions in marine protected areas. Biol Conserv 245:108553

James AN, Green MJB, Paine JR (1999) A global review of protected area budgets and staff. WCMC World Conservation Press, Cambridge, United Kingdom

Jones KR, Venter O, Fuller RA, Allan JR, Maxwell SL, Negret PJ, Watson JEM. One-third of global protected land is under intense human pressure. Science 360:788-791. DOI: 10.1126/science.aap9565

Kettunen M, Genovesi P, Gollasch S, et al (2009) Technical support to EU strategy on invasive alien species (IAS). Institute for European Environmental Policy (IEEP), Brussels, Belgium

Kourantidou M, Cuthbert RN, Haubrock P, et al (in press) Economic costs of invasive alien species in the Mediterranean basin. Neobiota

Kourantidou M, Kaiser BA (2021) Allocation of research resources for commercially valuable invasions: Norway's red king crab fishery. Fish Res 237:105871.

https://doi.org/https://doi.org/10.1016/j.fishres.2020.105871 
Latreille AC, Milesi P, Magalon H, et al (2019) High genetic diversity but no geographical structure of Aedes albopictus populations in Réunion Island. Parasit Vectors 12:597. https://doi.org/10.1186/s13071019-3840-x

Le Saout S, Hoffmann M, Shi Y, et al (2013) Protected Areas and Effective Biodiversity Conservation. Science (80- ) 342:803-805. https://doi.org/10.1126/science.1239268

Leroy B, Kramer AM, Vaissière A-C, et al (2020) Analysing global economic costs of invasive alien species with the invacost $\mathrm{R}$ package. bioRxiv. https://doi.org/10.1101/2020.12.10.419432

Leung B, Lodge DM, Finnoff D, et al (2002) An ounce of prevention or a pound of cure: bioeconomic risk analysis of invasive species. Proc R Soc London Ser B Biol Sci 269:2407-2413.

https://doi.org/doi:10.1098/rspb.2002.2179

Leverington F, Costa KL, Pavese $\mathrm{H}$, et al (2010) A global analysis of protected area management effectiveness. Environ Manage 46:685-698

Liebhold AM, Kean JM (2019) Eradication and containment of non-native forest insects: successes and failures. J Pest Sci (2004) 92:83-91. https://doi.org/10.1007/s10340-018-1056-z

Lindsey PA, Miller JRB, Petracca LS, et al (2018) More than $\$ 1$ billion needed annually to secure Africa's protected areas with lions. Proc Natl Acad Sci 115:E10788-E10796.

https://doi.org/10.1073/pnas.1805048115

Liu C, Diagne C, Angulo E, et al (in press) Economic costs of biological invasions in Asia. NeoBiota Liu X, Blackburn TM, Song T, et al (2020) Animal invaders threaten protected areas worldwide. Nat Commun 11:2892. https://doi.org/10.1038/s41467-020-16719-2

Lopez-Vaamonde C, Glavendekić M, Rosa Paiva M (2010) Invaded habitats. Chapter 4. BioRisk 4:46-50 Martins TLF, Brooke MDL, Hilton GM, et al (2006) Costing eradications of alien mammals from islands. Anim Conserv 9:439-444

Mazza G, Tricarico E (eds) (2018) Invasive Species and Human Health, Vol. 10. CABI

McCarthy DP, Donald PF, Scharlemann JPW, et al (2012) Financial costs of meeting global biodiversity conservation targets: current spending and unmet needs. Science (80- ) 338:946-949. https://doi.org/10.1126/science.1229803

McKinley JD, Sparks AH, Pede VO, Duff B (2012) An economic assessment of the impact of mango pulp weevil on the agricultural sector of Palawan, Philippines. Philppine Agric Sci 95:286-292

Moodley D, Foxcroft LC, Novoa A, et al (2020) Invasive alien species add to the uncertain future of protected areas. NeoBiota 57:1-5. https://doi.org/10.3897/neobiota.57.52188 
Nuñez MA, Pauchard A (2010) Biological invasions in developing and developed countries: does one model fit all? Biol Invasions 12:707-714. https://doi.org/10.1007/s10530-009-9517-1

Paini DR, Sheppard AW, Cook DC, et al (2016) Global threat to agriculture from invasive species. Proc Natl Acad Sci 113:7575-7579

Pejchar L, Mooney HA (2009) Invasive species, ecosystem services and human wellbeing. Trends Ecol Evol 24:497-504

Pimentel D, Zuniga R, Morrison D (2005) Update on the environmental and economic costs associated with alien-invasive species in the United States. Ecol Econ 52:273-288

Pratt CF, Constantine KL, Murphy ST (2017) Economic impacts of invasive alien species on African smallholder livelihoods. Glob Food Sec 14:31-37

Pyšek P, Hulme PE, Simberloff D, et al (2020) Scientists' warning on invasive alien species. Biol Rev 95:1511-1534. https://doi.org/10.1111/brv.12627

Pyšek P, Pergl J, Essl F, et al (2017) Naturalized alien flora of the world: species diversity, taxonomic and phylogenetic patterns, geographic distribution and global hotspots of plant invasion. Preslia 89:203-274

Pysek P, Richardson DM, Pergl J, et al (2008) Geographical and taxonomic biases in invasion ecology. Trends Ecol Evol 23:237-244. https://doi.org/https://doi.org/10.1016/j.tree.2008.02.002

Renault D, Angulo E, Cuthbert RN, Haubrock PJ, Capinha C, Kramer AM, Diagne C, Courchamp F (in this issue) The magnitude, diversity, and distribution of the economic costs of invasive terrestrial invertebrates worldwide. Biol Invasions

Ricciardi A, lacarella JC, Aldridge DC, et al (2021) Four priority areas to advance invasion science in the face of rapid environmental change. Environ Rev In press: https://doi.org/10.1139/er-2020-0088

Richardson DM, Abrahams B, Boshoff N, et al (2020) South Africa's Centre for Invasion Biology: An Experiment in Invasion Science for Society BT - Biological Invasions in South Africa. In: van Wilgen BW, Measey J, Richardson DM, et al. (eds) Biological Invasions in South Africa, Invading N. Springer International Publishing, Cham, pp 879-914

Richardson DM, Rejmánek M (2011) Trees and shrubs as invasive alien species - a global review. Divers Distrib 17:788-809

Rico-Sánchez AE, Haubrock PJ, Cuthbert RN, et al (in press) Economic costs of invasive alien species in Mexico. NeoBiota

Rico-Sánchez AE, Sundermann A, López-López E, Torres-Olvera MJ, Mueller SA, Haubrock PJ (2020). Biological diversity in protected areas: Not yet known but already threatened. Global Ecol Conserv 
Robertson PA, Mill A, Novoa A, et al (2020) A proposed unified framework to describe the management of biological invasions. Biol Invasions 22: 2633-2645. https://doi.org/10.1007/s10530-020-02298-2

Rodrigues ASL, Andelman SJ, Bakarr MI, et al (2004) Effectiveness of the global protected area network in representing species diversity. Nature 428:640-643. https://doi.org/https://doi.org/10.1038/nature02422

Rodrigues ASL, Gaston KJ (2001) How large do reserve networks need to be? Ecol Lett 4:602-609. https://doi.org/https://doi.org/10.1046/j.1461-0248.2001.00275.x

Scalera R (2010) How much is Europe spending on invasive alien species? Biol Invasions 12:173-177. https://doi.org/10.1007/s10530-009-9440-5

Schaffner F, Medlock JM, Van Bortel W (2013) Public health significance of invasive mosquitoes in Europe. Clin Microbiol Infect 19:685-692. https://doi.org/10.1111/1469-0691.12189

Schaffner U, Steinbach S, Sun Y, et al (2020) Biological weed control to relieve millions from Ambrosia allergies in Europe. Nat Commun 11:1745. https://doi.org/10.1038/s41467-020-15586-1

Seebens H, Bacher S, Blackburn TM, et al (2020) Projecting the continental accumulation of alien species through to 2050. Glob Chang Biol 27:970-982. https://doi.org/https://doi.org/10.1111/gcb.15333

Seebens H, Blackburn TM, Dyer EE, et al (2017) No saturation in the accumulation of alien species worldwide. Nat Commun 8:1-9. https://doi.org/10.1038/ncomms14435

Shackleton RT, Bertzky B, Wood LE, et al (2020a) Biological invasions in World Heritage Sites: current status and a proposed monitoring and reporting framework. Biodivers Conserv 29:3327-3347. https://doi.org/10.1007/s10531-020-02026-1

Shackleton RT, Foxcroft LC, Pyšek P, et al (2020b) Assessing biological invasions in protected areas after 30 years: Revisiting nature reserves targeted by the 1980s SCOPE programme. Biol Conserv 243:108424. https://doi.org/https://doi.org/10.1016/j.biocon.2020.108424

Strydom M, Veldtman R, Ngwenya MZ, Esler KJ (2017) Invasive Australian Acacia seed banks: Size and relationship with stem diameter in the presence of gall-forming biological control agents. PLoS One 12:e0181763. https://doi.org/https://doi.org/10.1371/journal.pone.0181763

Trueman M, Atkinson R, Guézou A, Wurm P (2010) Residence time and human-mediated propagule pressure at work in the alien flora of Galapagos. Biol Invasions 12:3949I3960

UNEP-WCMC, IUCN (2019) Protected Planet: The World Database on Protected Areas (WDPA) [Online] Cambridge, UK: UNEP-WCMC and IUCN. www.protectedplanet.net 
van Wilgen BW, Khan A, Marais C (2010) Changing Perspectives on Managing Biological Invasions: Insights from South Africa and the Working for Water programme. Fifty Years Invasion Ecol. 377-393

van Wilgen BW, Measey J, Richardson DM, et al (2020) Biological Invasions in South Africa: An Overview. In: van Wilgen BW, Measey J, Richardson DM, et al. (eds) Biological Invasions in South Africa, Invading N. Springer International Publishing, Cham, pp 3-31

Vilà M, Weber E, D’Antonio CM (2000) Conservation implications of invasion by plant hybridization. Biol Invasions 2:207-217

Vitousek PM (1990) Biological invasions and ecosystem processes - towards an integration of population biology and ecosystem studies. Oikos 57:7-13

Warren II RJ, King JR, Tarsa C, et al (2017) A systematic review of context bias in invasion biology. PLoS One 12:e0182502

Wickham H (2016) ggplot2: Elegant Graphics for Data Analysis

Wilkie DS, Carpenter JF, Zhang Q (2001) The under-financing of protected areas in the Congo Basin: so many parks and so little willingness to pay. Biodivers Conserv 10:691-709

Xu H, Ding H, Li M, et al (2006) The distribution and economic losses of alien species invasion to China. Biol Invasions 8:1495-1500

Zenni RD, Nuñez MA (2013) The elephant in the room: the role of failed invasions in understanding invasion biology. Oikos 122:801-815. https://doi.org/https://doi.org/10.1111/j.1600-0706.2012.00254.x

Ziller SR, Dechoum MS, Silveira RAD, et al (2020) A priority-setting scheme for the management of invasive non-native species in protected areas. NeoBiota 62:591-606.

https://doi.org/10.3897/neobiota.62.52633

\section{Figures}




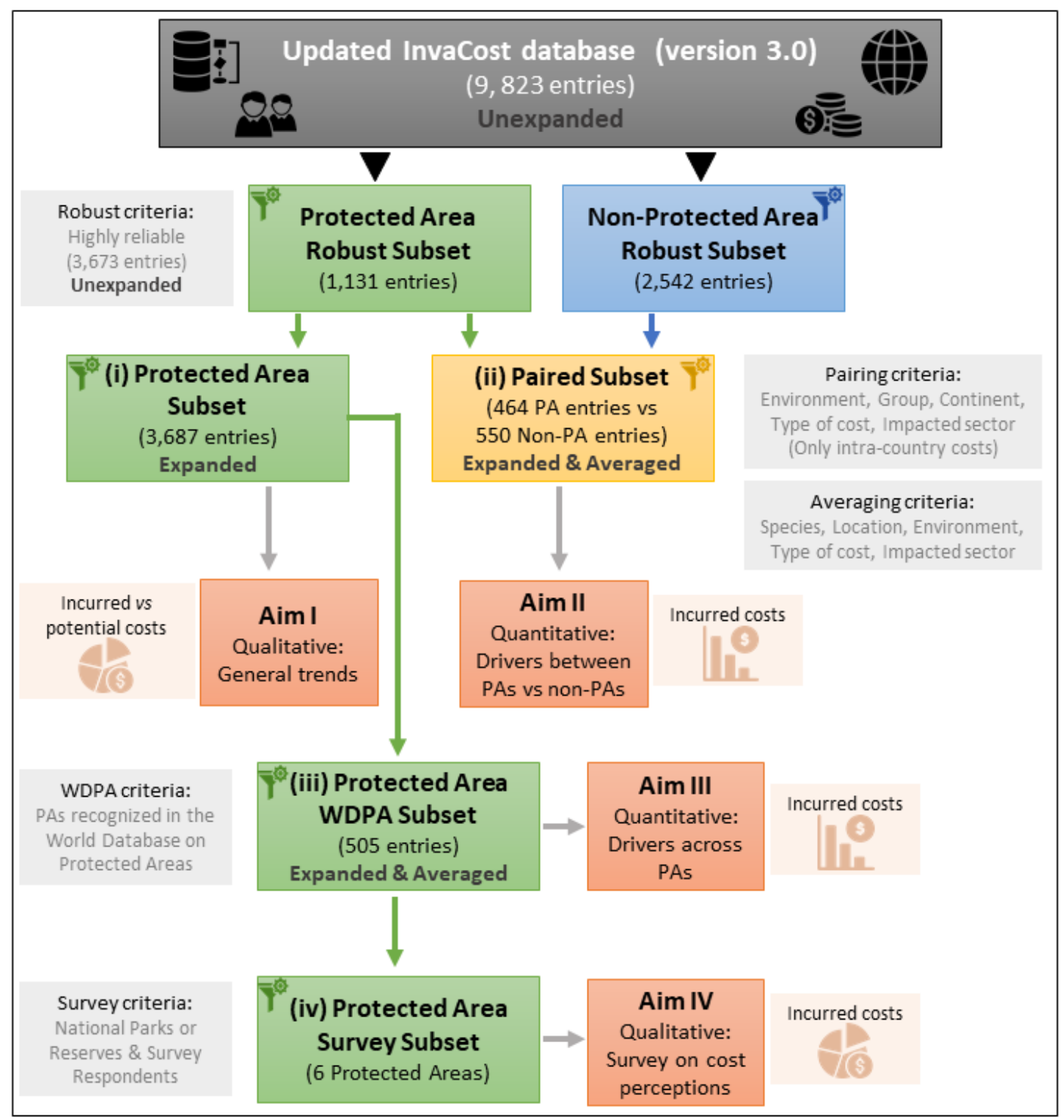

\section{Figure 1}

Workflow chart detailing the processes of filtering and the eligibility of cost entries included in the quantitative and qualitative syntheses. 
(a)

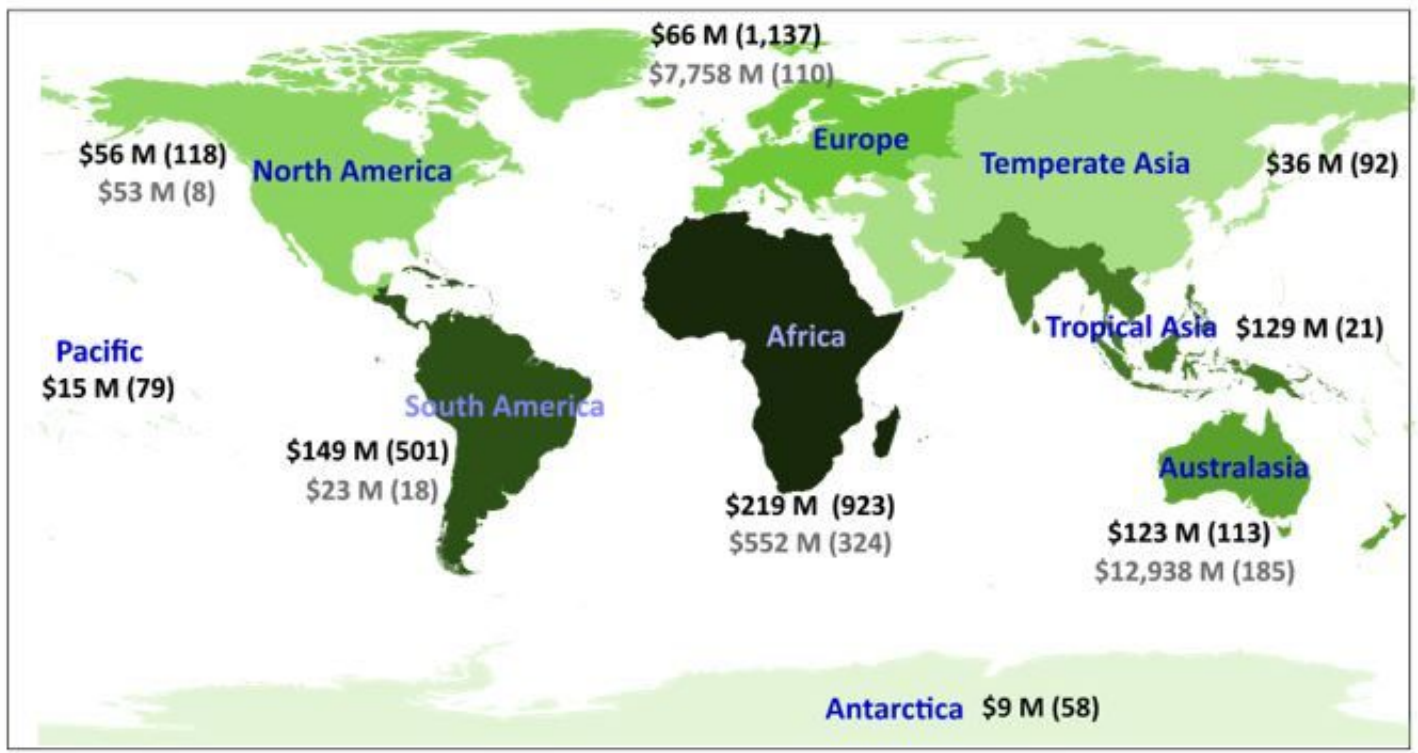

(b)

Breakdown of costs by cost type

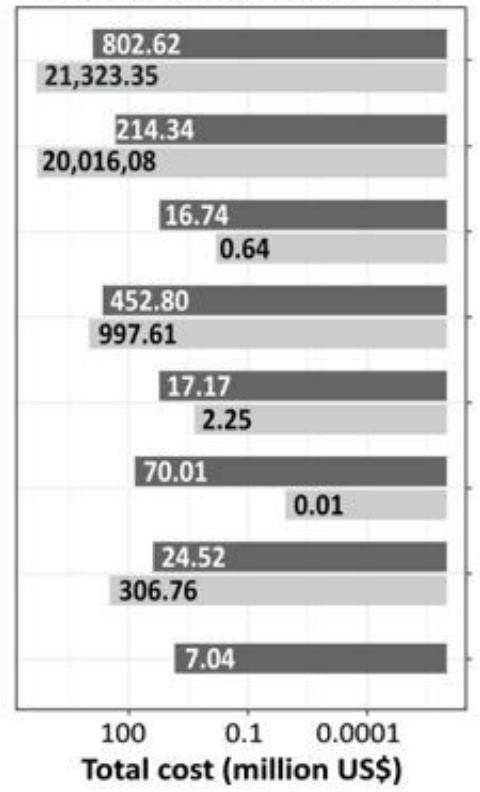

All costs

Damage

Pre-invasion management

Post-invasion management

Kowledge \& funding

Mixed management

Mixed management \& damage

Mixed/Unspecified

Proportion of costs by impacted sector

- Observed

Total cost (million US\$)

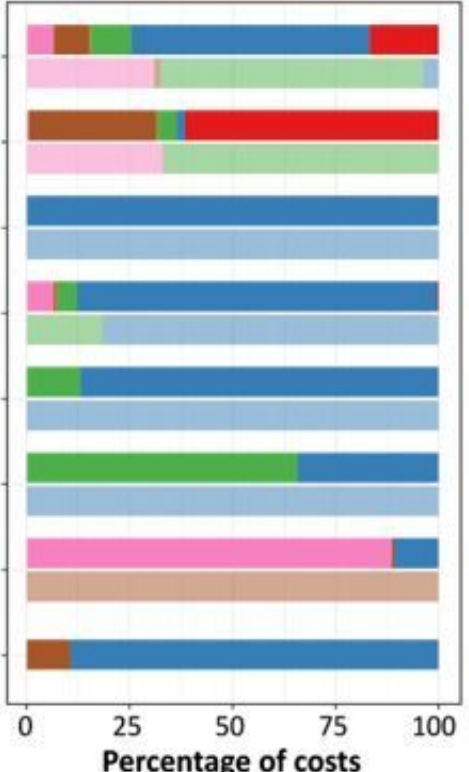

agriculture

authorities \& stakeholders

Environment

a Fishery

anorestry

Health

= Mixed

andic \& social welfare

\section{Figure 2}

Total observed and potential costs of invasive alien species (US\$ million) in protected areas, as well as reported cost entries, presented according to their: (a) spatial patterns across continents. The colour gradient on the map reflects the continent with the highest (i.e. dark) to lowest (i.e. light) observed costs. The total observed economic costs are displayed in black, potential costs are in grey and their corresponding number of cost entries are shown in parenthesis; and (b) cost type and associated impacted sectors. For the impacted sector, upper (opaque) bars match observed costs and lower (semitransparent) bars match potential costs. Note: The designations employed and the presentation of the material on this map do not imply the expression of any opinion whatsoever on the part of Research Square concerning the legal status of any country, territory, city or area or of its authorities, or concerning the delimitation of its frontiers or boundaries. This map has been provided by the authors. 


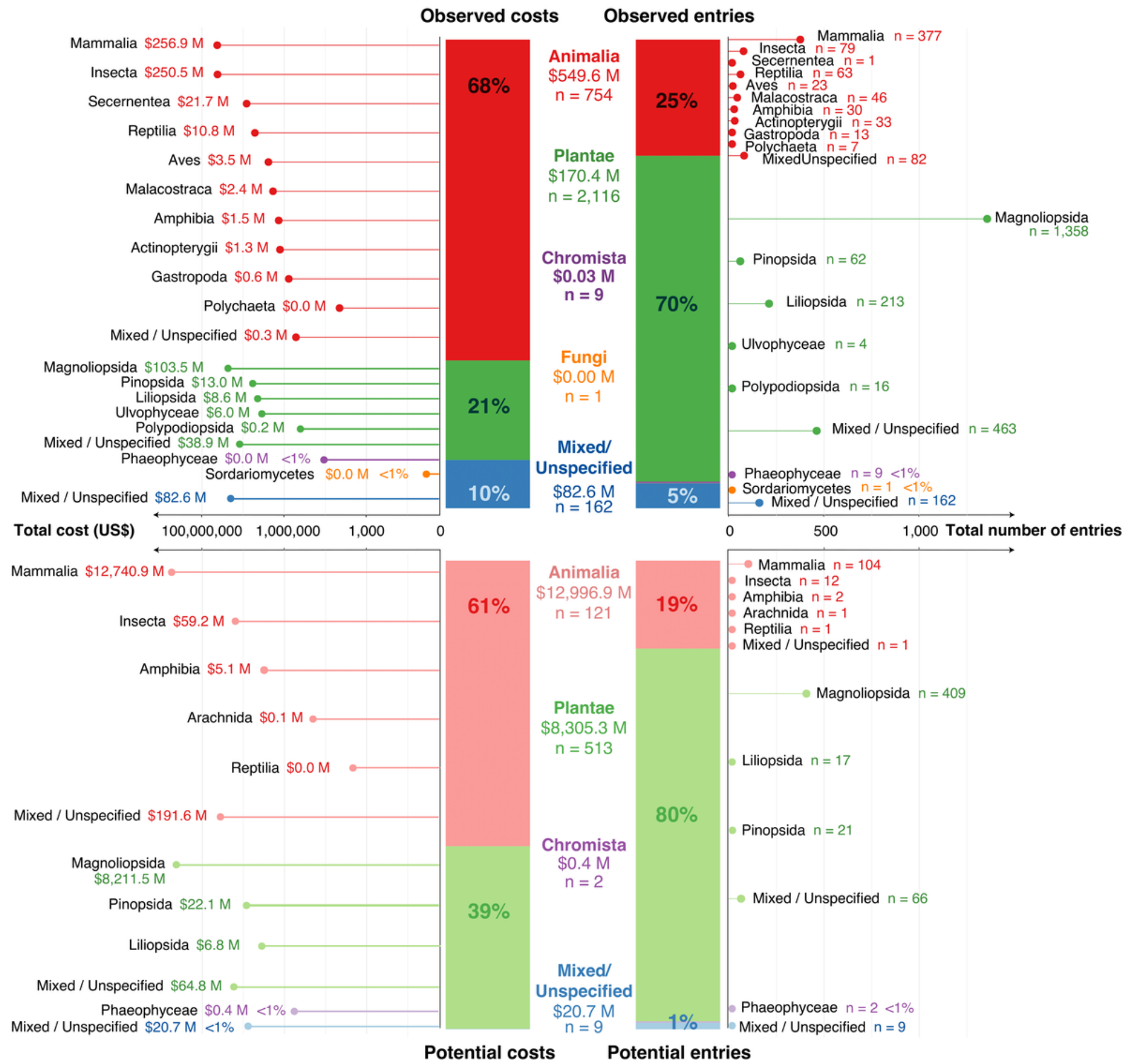

Figure 3

Taxonomic distribution of cost estimates (US\$ million, left panels) and cost entries (right panel). Coloured bars represent the percentage of costs by kingdoms and lollipops depict total economic costs of the associated classes. 
(a)
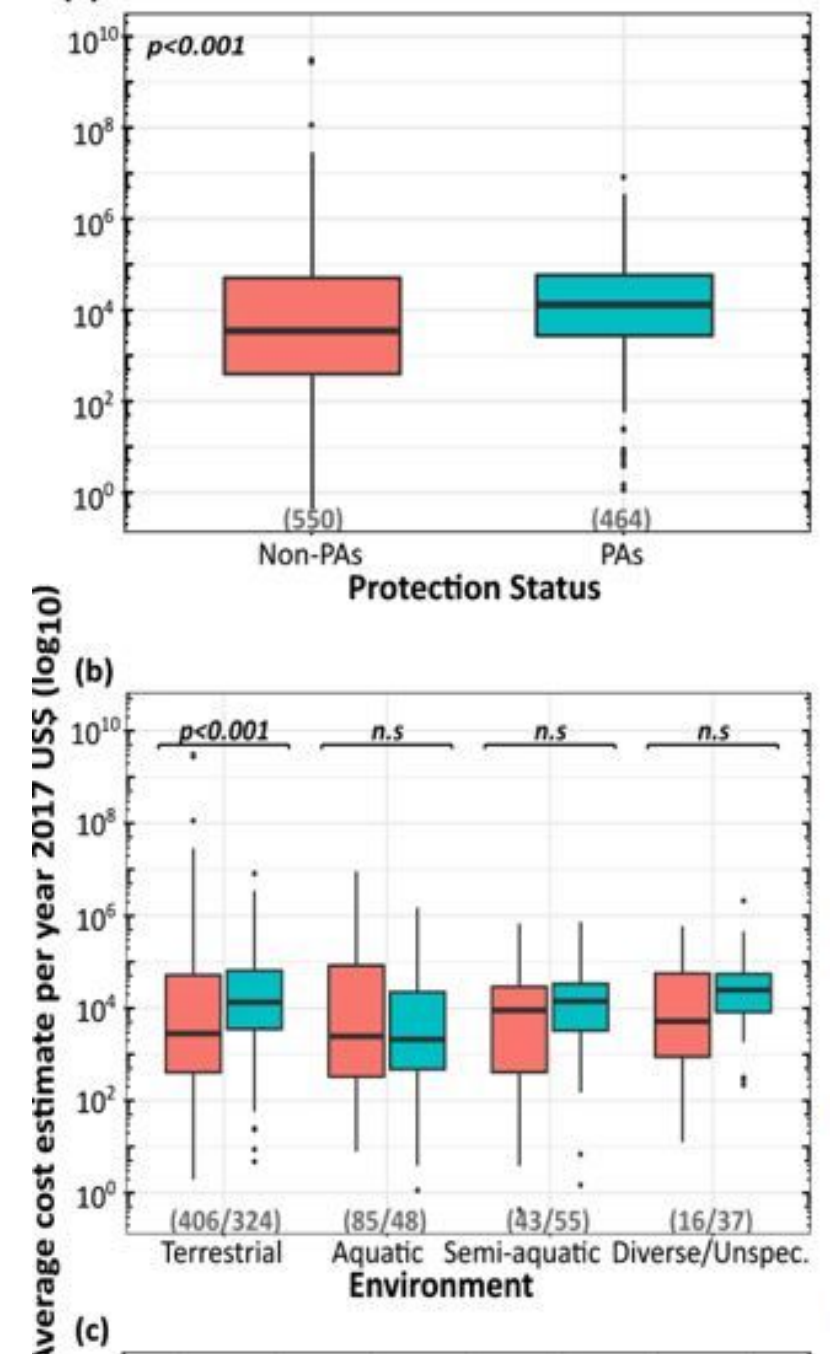

(c)

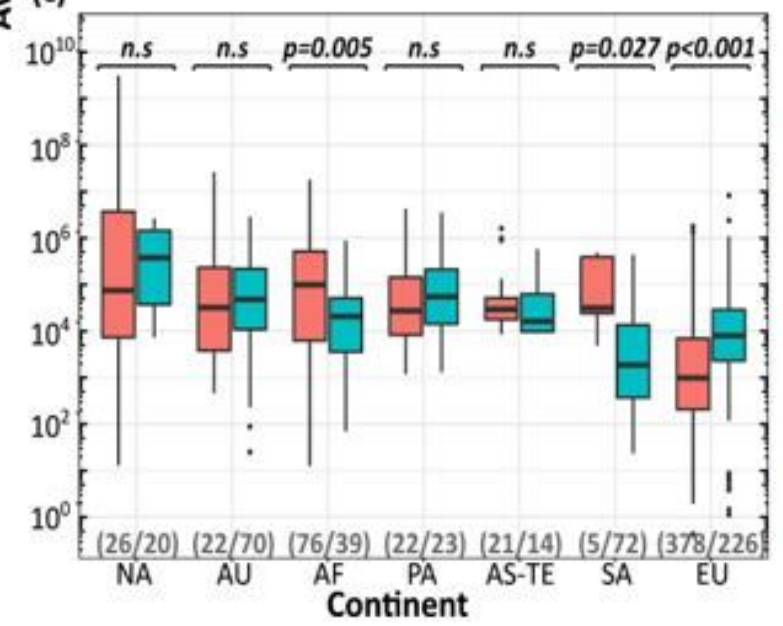

(e)
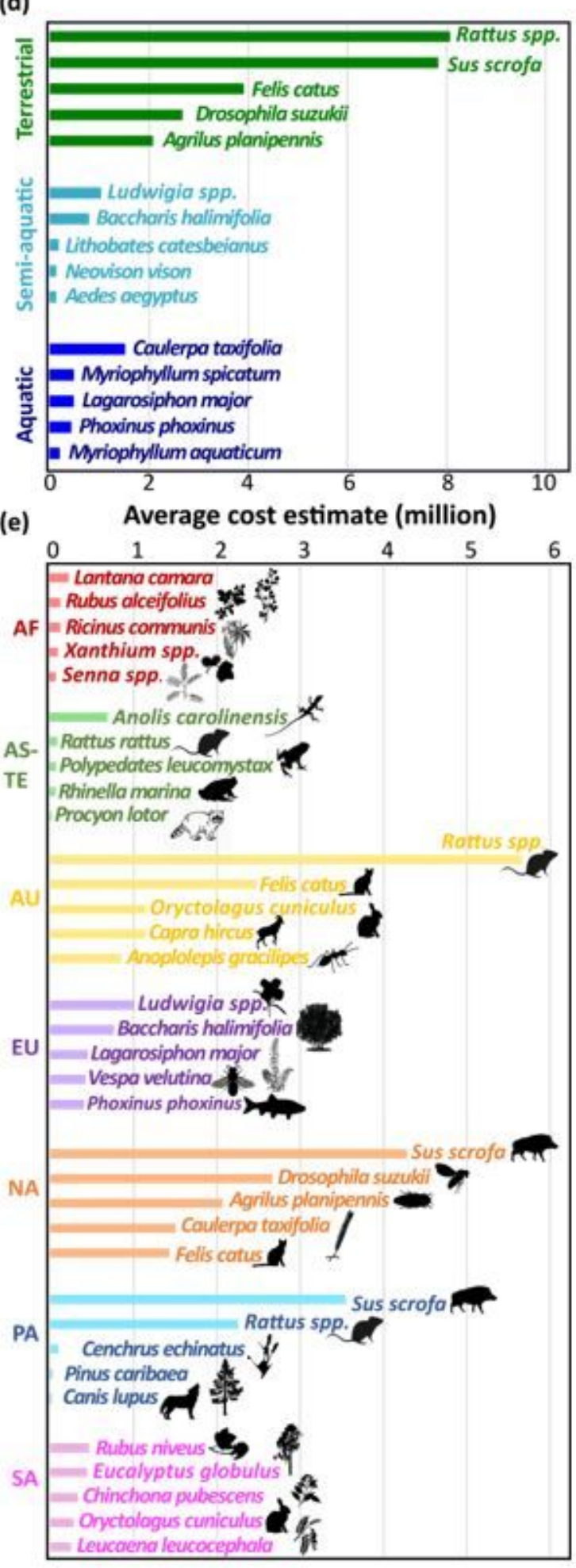

Figure 4

Distribution of the mean economic observed cost estimates (log10 scale) incurred by species across: (a) non-protected and protected areas; (b) environments with different land protection statuses; and (c) continents with different land protection statuses (NA=North America, AU=Australasia, AF=Africa, $\mathrm{PA}=$ Pacific, AS-TE=Asia-Temperate, $\mathrm{SA}=$ South America, $\mathrm{EU}=$ Europe). Bar plots depict the distinction of reported costs in protected areas for the top five costliest species across (d) environments and (e) 
continents. Boxplots display median (line), interquartile range (box) and range (whiskers), and solid circles display outliers. Significant differences between PAs and non-PAs for each category are marked using p-values above each boxplot pair, and was tested using a Kruskal Wallis rank sum test for (a) and Wilcoxon signed-rank post hoc comparisons for $(b, c)$. Sample sizes are in brackets below each box. Most cliparts come from phylopic.org.
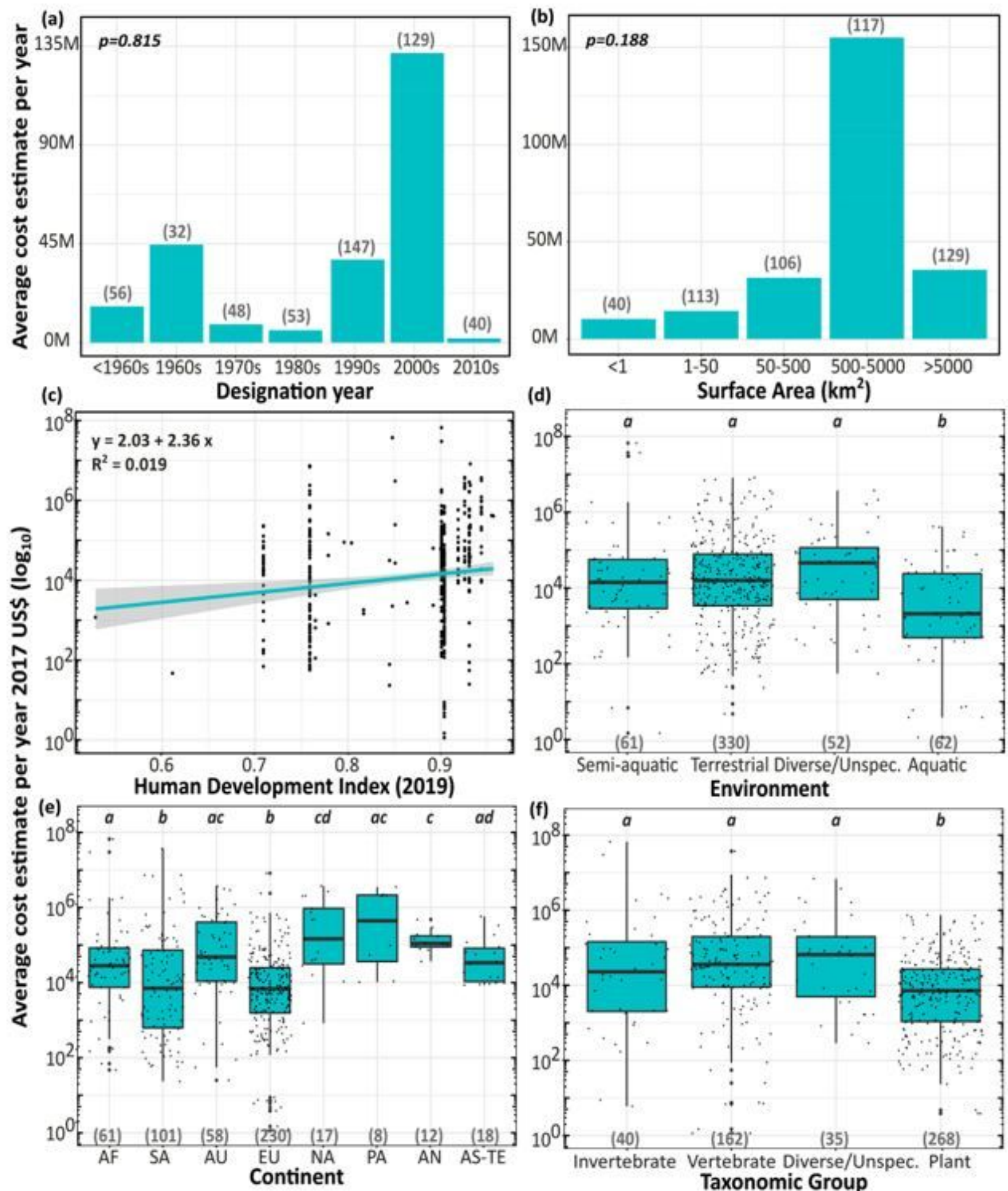

(d)

Surface Area $\left(\mathrm{km}^{2}\right)$
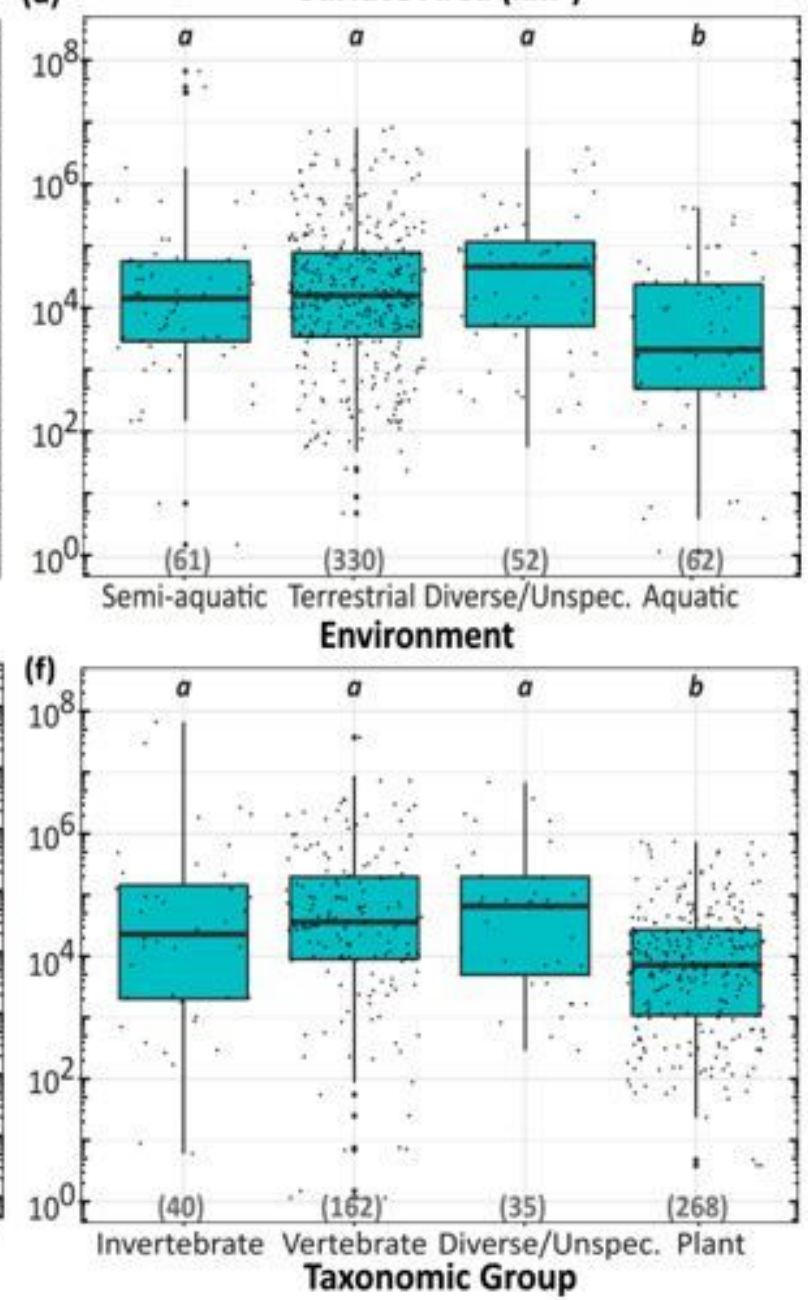

Figure 5 
The relationship between mean costs and (a) the year in which the PA was designated (y-axis in US\$ million); (b) the size of the PA (y-axis in US\$ million); (c) the invaded countries' HDI; (d) the environment in which the impacted PA is located; (e) the continent in which the impacted PA is located (AF=Africa, $\mathrm{SA}=$ South America, $\mathrm{AU}=$ Australasia, $\mathrm{EU}=$ Europe, $\mathrm{NA}=$ North America, $\mathrm{PA}=\mathrm{Pacific}, \mathrm{AN}=$ Antarctica, AS$\mathrm{TE}=$ Asia-Temperate); and ( $\mathrm{f}$ ) the taxonomic group of the invasive species. Categories with different letters show significant differences between them, which were tested using the Wilcoxon signed-rank test. For the boxplots, the solid line shows the median, the lower and upper hinges of the box represent the lower and upper quartiles, the whiskers indicate the range of the data, solid circles are outliers, and solid squares depict the observed data points. Sample sizes are in brackets below each box.

\section{Supplementary Files}

This is a list of supplementary files associated with this preprint. Click to download.

- ESM1.pdf

- ESM2.xlsx

- ESM3.pdf

- ESM4.pdf

- ESM5.pdf

- ESM6.pdf

- ESM7.pdf

- ESM8.pdf

- ESM9.pdf 